Portland State University

PDXScholar

TREC Final Reports

Transportation Research and Education Center

(TREC)

7-2017

\title{
What Do We Know About Location Affordability in U.S. Shrinking Cities?
}

Joanna Ganning

Cleveland State University

Jenna Rosie Tighe

Cleveland State University

Follow this and additional works at: https://pdxscholar.library.pdx.edu/trec_reports

Part of the Transportation Commons, Urban Studies Commons, and the Urban Studies and Planning Commons

Let us know how access to this document benefits you.

\section{Recommended Citation}

Ganning, J. and Tighe, J. R. What Do We Know about Location Affordability in U.S. Shrinking Cities? NITCRR-872. Portland, OR: Transportation Research and Education Center (TREC), 2017. https://doi.org/ $10.15760 /$ trec. 177

This Report is brought to you for free and open access. It has been accepted for inclusion in TREC Final Reports by an authorized administrator of PDXScholar. Please contact us if we can make this document more accessible: pdxscholar@pdx.edu. 


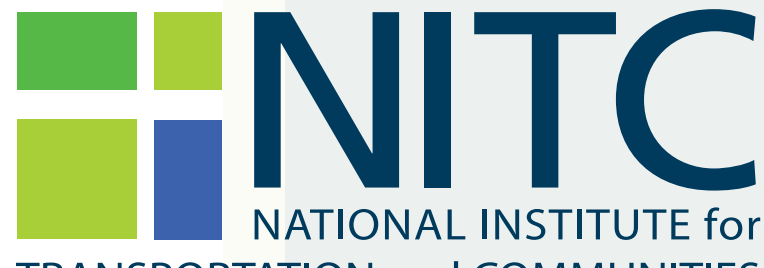

TRANSPORTATION and COMMUNITIES

FINAL REPORT

What do we know about Location Affordability in U.S. Shrinking Cities?

NITC-RR-872 July 2017

NITC is a U.S. Department of Transportation

national university transportation center.

HI! TREC 



\title{
WHAT DO WE KNOW ABOUT LOCATION AFFORDABILITY IN U.S. SHRINKING CITIES?
}

Final Report

NITC-RR-872

\author{
by \\ Joanna Ganning (PI) \\ J. Rosie Tighe
}

Cleveland State University

for

National Institute for Transportation and Communities (NITC)

P.O. Box 751

Portland, OR 97207
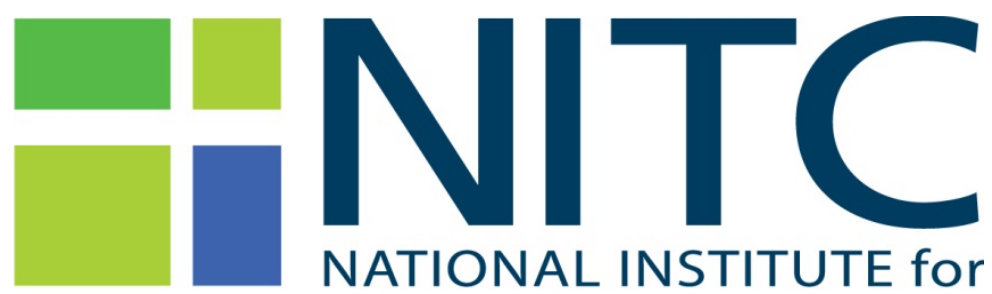

TRANSPORTATION and COMMUNITIES

July 2017 


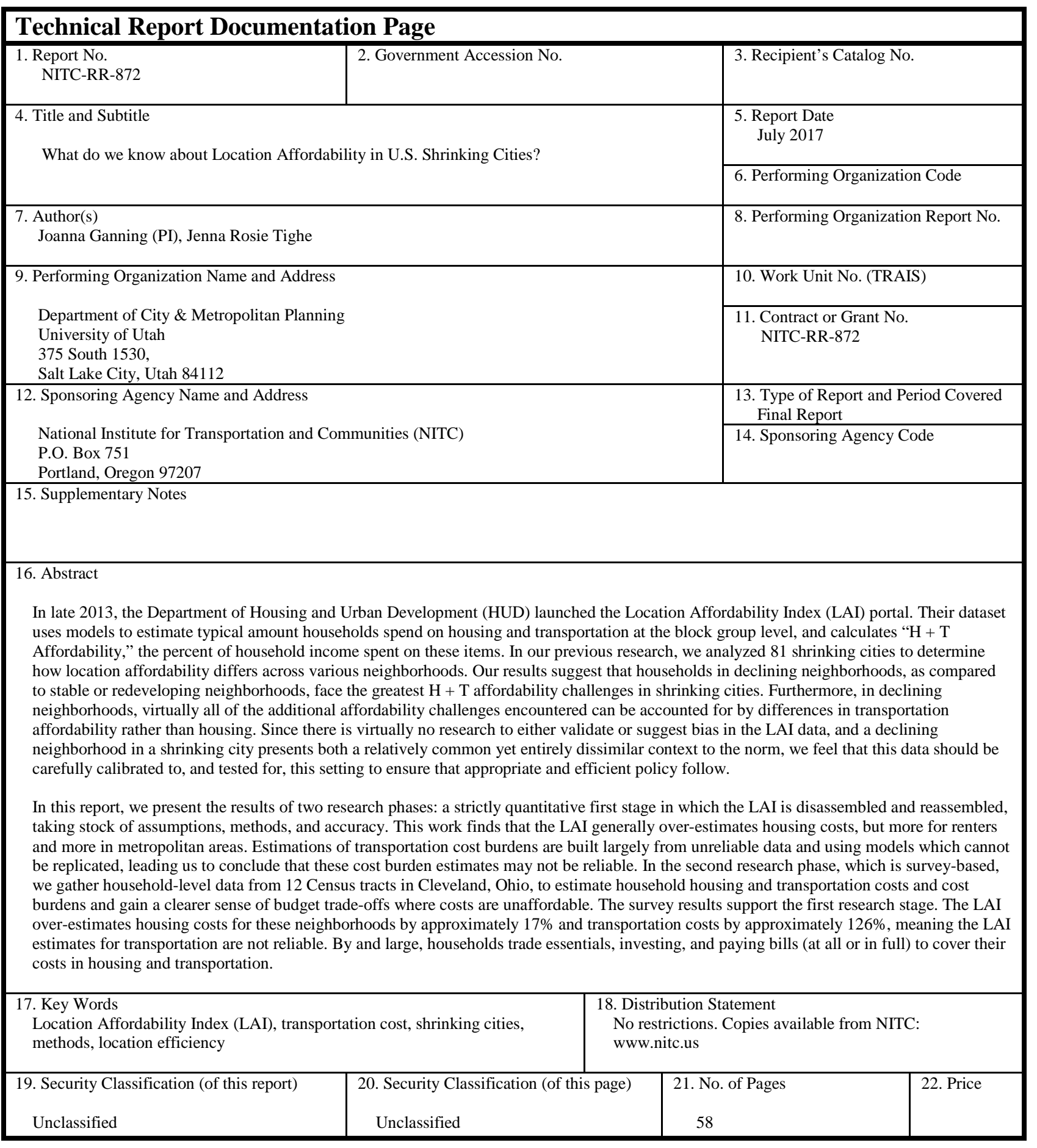




\section{ACKNOWLEDGEMENTS}

This project was funded by the National Institute for Transportation and Communities (NITC), in addition to The Greater Cleveland Regional Transit Authority. The project also benefitted from a match from the University of Utah and Cleveland State University. Furthermore, we acknowledge and thank the anonymous peer reviewers who provided immensely helpful insights and corrections to Chapter 1, which is published in Housing Policy Debate (Ganning, 2017).

\section{DISCLAIMER}

The contents of this report reflect the views of the authors, who are solely responsible for the facts and the accuracy of the material and information presented herein. This document is disseminated under the sponsorship of the U.S. Department of Transportation University Transportation Centers Program in the interest of information exchange. The U.S. Government assumes no liability for the contents or use thereof. The contents do not necessarily reflect the official views of the U.S. Government. This report does not constitute a standard, specification, or regulation.

\section{RECOMMENDED CITATION}

Ganning, Joanna, and J. Rosie Tighe. What do we know about Location Affordability in U.S. Shrinking Cities? NITC-RR-872. Portland, OR: Transportation Research and Education Center (TREC), 2017. 


\section{TABLE OF CONTENTS}

EXECUTIVE SUMMARY 1

\subsection{IT'S GOOD BUT IS IT RIGHT? AN UNDER-THE-HOOD VIEW OF THE}

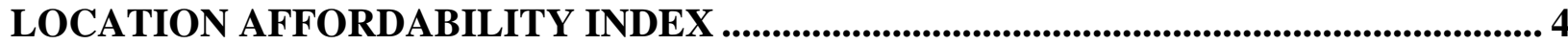

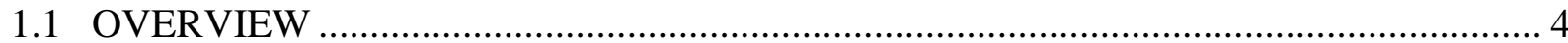

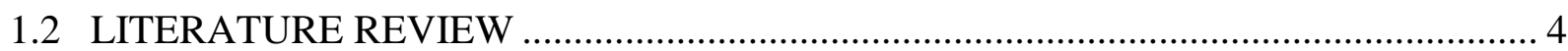

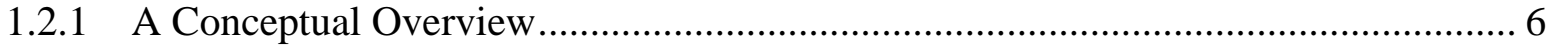

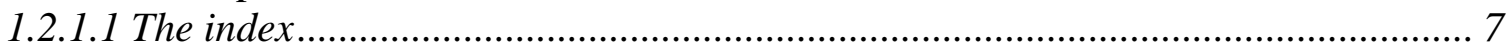

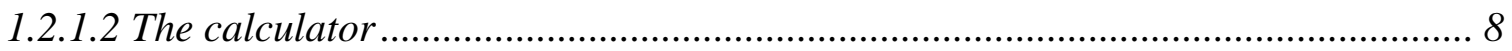

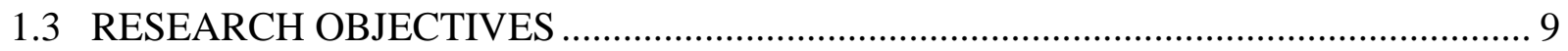

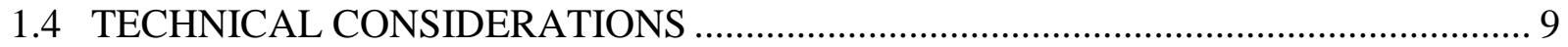

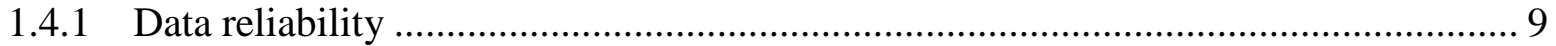

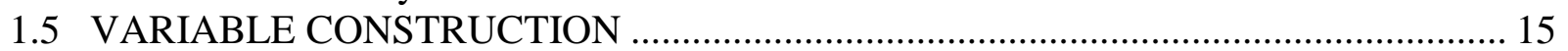

1.5.1 Representative reliability in employment densities .......................................... 15

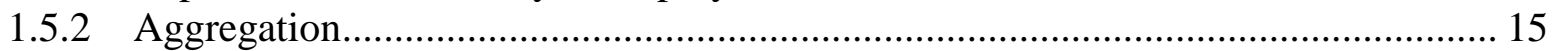

1.5.2.1 Creating a weighted average from data representing medians........................... 16

1.5.2.2 Using a weighting scheme misaligned with variable definition .......................... 17

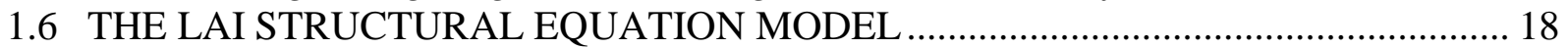

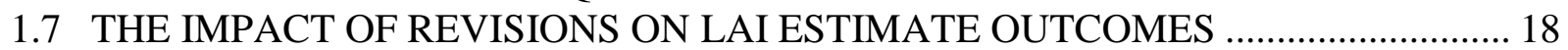

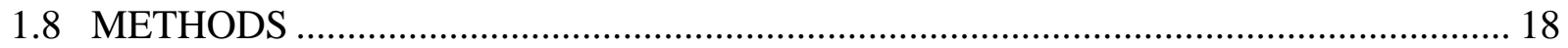

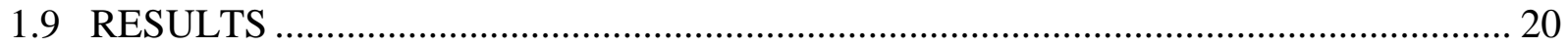

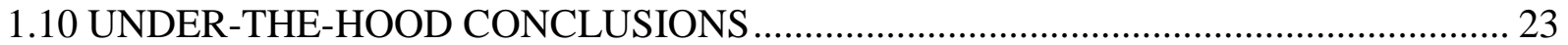

\subsection{ON THE GROUND: WHAT DO WE KNOW ABOUT LOCATION}

AFFORDABILITY IN U.S. SHRINKING CITIES? ................................................... 27

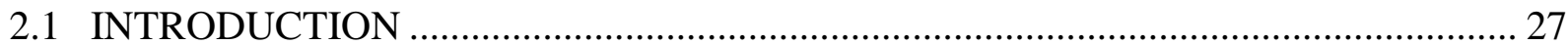

2.2 TRANSPORTATION NEEDS OF POOR HOUSEHOLDS AND NEIGHBORHOODS IN

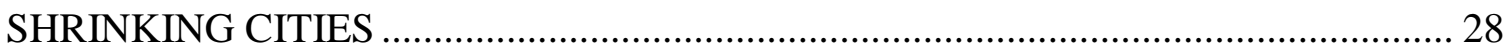

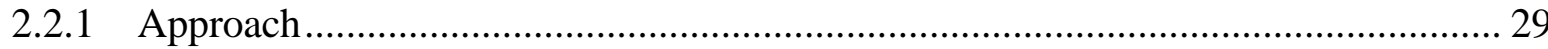

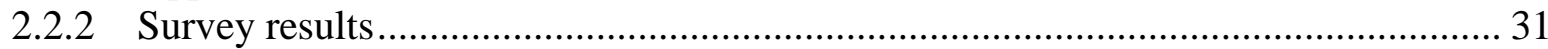

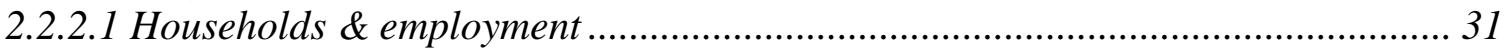

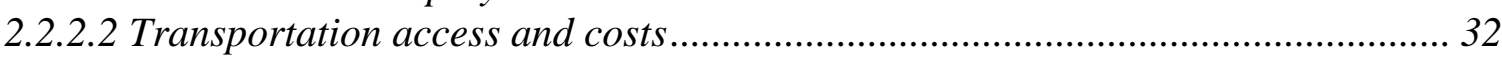

2.2.3 Analysis........................................................................................................ 33

2.2.3.1 Comparing LAI and survey-based estimates of housing and transportation costs

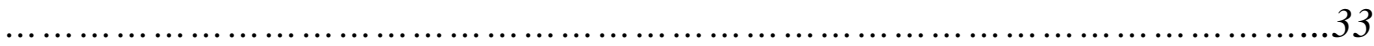

2.2.3.2 Assessing the trade-offs households engage in to cope with unaffordable costs.. 36

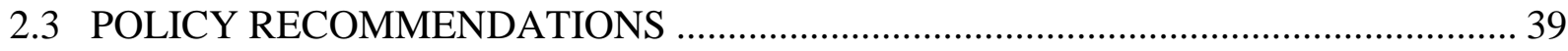

2.3.1 Rideshare and van pools .............................................................................. 40

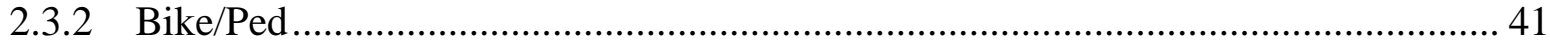

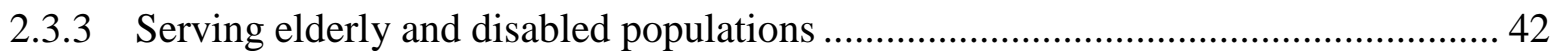

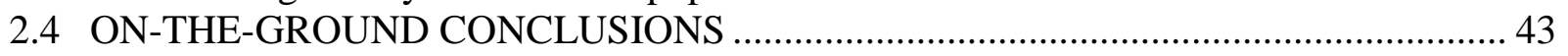

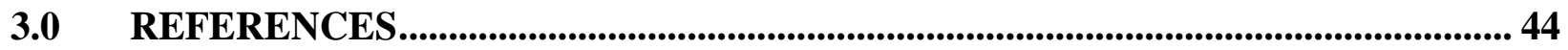




\section{LIST OF TABLES}

Table 1.1: Reliability of LAI SEM inputs at block group level............................................. 12

Table 1.2: Reliability of LAI SEM inputs at the Census tract level ......................................... 13

Table 1.3. Hypothetical case used to illustrate inappropriate aggregation method ..................... 17

Table 1.4. Aggregating area-based variables according to household weighting introduces

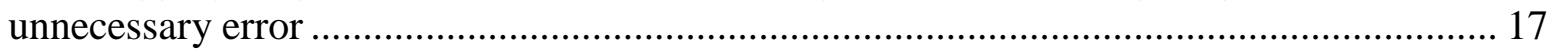

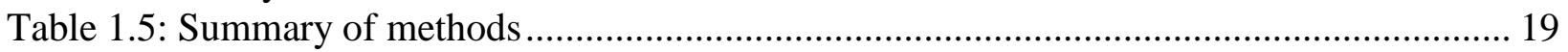

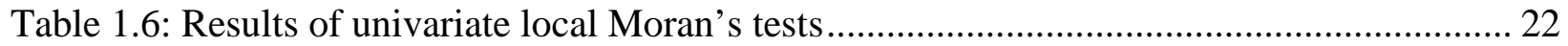

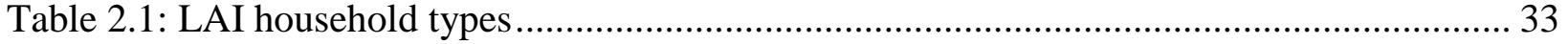

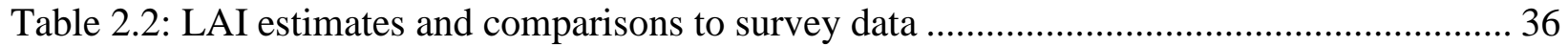

Table 2.3: H+T affordability across neighborhoods ...................................................... 37

\section{LIST OF FIGURES}

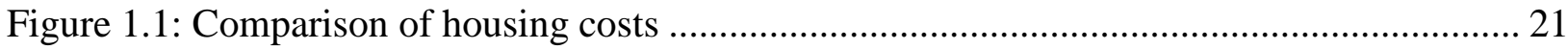

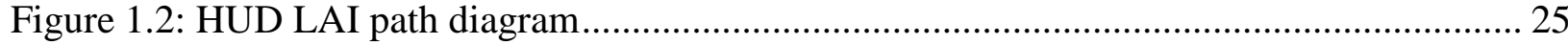

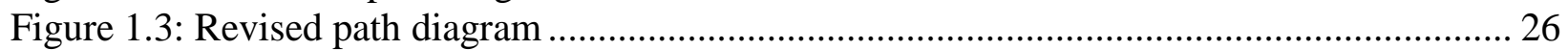

Figure 2.1: Map of Cleveland neighborhoods with surveyed tracts indicated ........................... 31

Figure 2.2: Survey results compared to LAI “moderate-income” and “single-parent” household

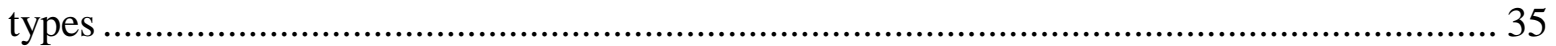

Figure 2.3: Survey results compared to LAI “retired-couple” and "single-parent” household type

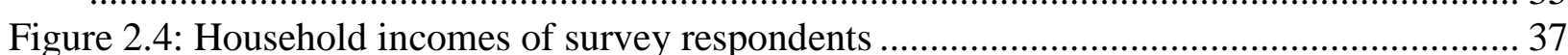

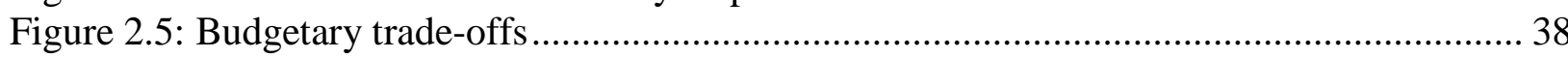

Figure 2.6: GCRTA priority corridors and survey neighborhoods ........................................ 40 


\section{EXECUTIVE SUMMARY}

In 2013, the Department of Housing and Urban Development (HUD) released the Location Affordability Index (LAI) as an online portal and downloadable data set. The LAI has elevated the U.S. conversation on affordability, moving beyond housing to include transportation and access to opportunities, and has been used in state and federal programming, by researchers, and by private households. The dataset uses models to estimate what households spend on housing and transportation, and calculates " $\mathrm{H}+\mathrm{T}$ Affordability," the percent of household income spent on these items. However, there is virtually no validation of the estimates in any setting, and no studies delving into how accurate the estimates are in "shrinking" or weak-market cities, which represent a distinct context.

While some researchers have noted concerns and potential limitations of the data, none have provided practitioners and researchers with an under-the-hood view of the data, analysis of its reliability or validity, or its conceptual limitations. As a result of completing such an analysis, we recommend methodological improvements dealing with issues of variable construction, aggregation, and modeling. A recreation of the LAI at the Census tract level suggests the LAI overestimates both costs and cost burden, but especially among renters, and especially in metropolitan areas. On the transportation side, model re-creation requires partnership and resourcing to both gain access to restricted data and to develop a reliable database on transit supply and use.

To further understand the real costs of housing and transportation in a declining context, we implemented a household survey to determine whether the assumptions made in the literature and the LAI regarding household expenditures and transportation accessibility hold when analyzing shrinking cities - generally cities characterized by a long-term loss in occupied housing units. We present results from 12 Census tracts in Cleveland, Ohio, a prototypical shrinking city. The 12 tracts were chosen to represent redeveloping, stable, and declining neighborhoods. We conclude by synthesizing our analyses and providing recommendations for improving the LAI data for shrinking cities, and for informing local transportation policy to improve livability.

We completed the project in two major phases. In the first, we rebuilt the LAI from scratch to examine its assumptions and potential shortcomings for a shrinking city context. In this phase we evaluated margins of error for input variables, variable construction for larger geographic areas than the block group (the focal point of HUD's LAI), and modeling considerations. The key conclusions of this research phase include the following:

- The American Community Survey data used to disaggregate transit costs and allocate them to households fails to pass basic reliability metrics for virtually all Census tracts in the state of Ohio. The automobile-based costs are estimated through a regression model which cannot be fully replicated. The strongest recommendation of this research is that 
HUD and its partners work to improve the reliability and reproducibility of the transportation cost estimates.

- The margins of error in American Community Survey data for many input variables used in the LAI indicate poor reliability at the block group geography. However, reliability is greatly improved in data covering the same metrics at the Census tract geography (the next larger geography in Census standard geography). To improve reliability, a tract-level LAI is recommended, rather than the block group-level index currently provided online.

- The LAI user's manual recommends that users estimate tract-level input variables and the LAI itself by weighting the block group LAI according to number of households. However, our research shows that households represent an appropriate weighting field in only some cases, and when applied inappropriately to variables introduces error. This project developed R-based code to recalculate the variables from their raw inputs.

- After reproducing the LAI in its entirety and producing housing cost estimates, a comparison suggests the estimates published by HUD over-estimate both housing cost and housing cost burden. Over-estimates are larger for renter households, and larger in metropolitan areas.

- For audiences, it is difficult to understand how to use the LAI, owing largely to its reliance on eight prototypical household types. This theme is explored further in our survey-based research.

In the second phase of the project we developed, deployed, and analyzed data from a householdlevel survey in 12 Census tracts in Cleveland, Ohio. The survey sought to better understand household trade-offs for unaffordable transportation costs, and sought to better estimate household-level transportation costs as a means of assessing the quality of those published by HUD. The key conclusions of this research phase include the following:

- Following the last bullet point from Phase 1, our survey found that less than $9 \%$ of households resemble any household type used by the LAI.

- Also confirming findings from Phase 1, the survey shows that the published LAI estimates likely over-estimate housing costs. The survey indicates that the published LAI also over-estimates transportation costs, and does so at a much higher margin of error than in the housing case. However, these findings come with several caveats:

o Discrepancies between the LAI and the survey results depend significantly on which household type you assume in the LAI data. Since only $9 \%$ of the sample matches any household type, choosing an appropriate one is difficult.

o Discrepancies between the LAI and the survey results depend on whether you use the mean or the median of the survey results. For the LAI, because it assumes all households are identical, the mean and median are equal. In survey data, the mean and median are not equal. The published LAI more closely matches the mean total 
cost $(\mathrm{H}+\mathrm{T})$ for Census tracts but use of medians is the norm in data on incomes and expenses (and is the moment reported herein).

- Despite the finding that the LAI overestimates both housing and transportation costs for households in our sample neighborhoods, most respondents to our survey face $\mathrm{H}+\mathrm{T}$ costs that are unaffordable.

- Survey results show that when households must make tradeoffs to pay for transportation, two-thirds do so by foregoing paying (or by foregoing fully paying) bills, buying essentials (like food and clothing), paying down debt, paying for experiences for children (like field trips, educational opportunities, or sports equipment), and investing. Thus, for households facing these budgetary decisions, transportation costs more by imposing an out-of-pocket cost now, and the cost of interest on overdue bills or lost investment income in the future.

- Finally, our results indicate that many low-income households in shrinking cities lack mobility both in terms of housing and transportation. As employment suburbanizes but transit budgets remain stable or decline, residents may face increasing difficulties with access to jobs, school, or medical care. 


\subsection{IT'S GOOD BUT IS IT RIGHT? AN UNDER-THE-HOOD VIEW OF THE LOCATION AFFORDABILITY INDEX}

\subsection{OVERVIEW}

In 2013, the Department of Housing and Urban Development (HUD) released the Location Affordability Index (LAI) as an online portal and downloadable data set. HUD adopted and revised the LAI from its origin as the Center for Neighborhood Technology's $\mathrm{H}+\mathrm{T}$

Affordability Index. This database seeks to inform households and public agencies of the costs of living in various places, changing the discussion about affordability from one focused solely on housing to one inclusive of transportation costs. Numerous scholars have analyzed the LAI estimates, resulting in a special issue of Housing Policy Debate as well as other manuscripts.

These publications have addressed housing subsidies, mortgage risk, and racial disparities in costs, among other things. However, these manuscripts have not provided practitioners and researchers with an under-the-hood view of the data, analysis of its reliability or validity, or its conceptual limitations. As this manuscript shows, some elements of the LAI introduce either considerable error or the potential for considerable error. Many of those issues, based in variable construction, aggregation, and modeling decisions, can be fixed. Others - notably, data on transit use-are more problematic. If left unchecked, such error could misinform decisions regarding household location or public policy issues in housing or transportation-potentially costing private households or public agencies considerably. This manuscript uses data from across the state of Ohio, intending it as an illustrative case study of the national implications of the conceptual and technical bounds of the LAI.

Following a brief background section, Section 1 provides conceptual and technical overviews of the LAI. The following, more detailed Section 2 evaluates technical issues regarding data reliability, variable construction, aggregation, and the LAI's structural equation model (SEM). The final sub-section of Section 2 presents the methods and results of re-estimating the SEM. Finally, the manuscript concludes with recommendations for LAI revision, either by HUD or for researchers seeking to replicate the index for later years, specific geographies, or to mitigate a selection of the issues raised.

\subsection{LITERATURE REVIEW}

In the 1990s President Bill Clinton focused national economic development policy on integrating social and economic systems, using policies such as Empowerment Zones (created through the Omnibus Budget Reconciliation Act of 1993). Under the George W. Bush White House, policy changed but retained a focus on reducing housing discrimination and addressing some placebased development issues. One example is brownfield redevelopment, addressed via the Small 
Business Liability Relief and Brownfields Revitalization Act. President Obama continued in the direction of focusing national economic development policy on place-based change, by emphasizing strong cities as building blocks for regional development, through efforts such as the Smart Cities Initiative. Over President Obama's two terms the national discussion about place-based development evolved to consider more broad-based evaluations of affordability, and the interplay of transportation systems, economic opportunity, and housing development that influences neighborhood vitality. The Obama administration's Partnership for Sustainable Communities represents one effort toward advancing this conversation. The LAI is an initiative of that partnership (HUD, n.d.-a).

The LAI represents more than a shift in the conversation about affordability; The LAI has direct bearing on federal policy through HUD’s Affirmatively Furthering Fair Housing (AFFH) program. The effort, an executive order of President Obama, requires some HUD grantees to complete Assessments of Fair Housing. The Assessment Tool includes (among other data points) eight indices "to help inform communities about segregation in their jurisdiction and region, as well as about disparities in access to opportunity” (Abt Associates \& Mast, 2015, p. 10). Two of those indices use as their basis variables produced in the LAI - the Low Transportation Cost Index and the Transit Trips Index. Thus, the recommendations drawn from this manuscript's findings could affect not only the LAI, which is a tool for practitioners and researchers, but also policy in the form of AFFH. States such as Minnesota and Illinois have also adopted policies relying on location affordability databases (National Conference of State Legislatures, 2011).

The LAI also indirectly influences federal policy related to public housing programs and mortgage lending through peer-reviewed research. Several scholars have investigated the merit of adjusting subsidy levels or duration for public housing programs in scale with the presence of local amenities (Bieri \& Dawkins, 2016) and location efficiency (Lens \& Reina, 2016; Tremoulet \& Adkins, 2016). Kaza, Riley, Quercia, and Tian (2016) analyze mortgage performance and location efficiency, arguing that mortgage concessions for low-income families in high-efficiency locations may not be warranted.

The LAI's potential to influence local and regional policy provides the primary motivation for this manuscript. In many metropolitan regions, transit authorities increasingly acknowledge issues of racial and socioeconomic segregation and opportunity and promote goals of providing transit services where they will most benefit neighborhoods. This is the case, for instance, for the Cleveland Regional Transit Authority (henceforth "RTA"), which also faces a long-declining budget. With a high marginal utility of public dollars, and a high opportunity cost of investing, the RTA views location affordability as a potentially valuable tool in developing programming options. The RTA thereby joined this research effort as a match partner, enabling the work to use Cleveland as its case study setting for the evaluation of the LAI's reliability, validity, and applicability, as well as other research questions that lie beyond the scope of this manuscript. To avoid the bias that the MSA's distinct economic patterns might exert, this manuscript evaluates data across the state of Ohio.

Both HUD and scholars have previously identified some concerns regarding data reliability and validity in the LAI, but exploration of those concerns has almost universally ended at identification. HUD identifies two big-picture known concerns regarding the LAI. First, the models assume that all households within a block group match the household type for which 
estimates have been produced. This is neither realistic nor desirable. The effects of housing and household diversity number many, from encouraging aging-in-place to decreasing time on the market (for the latter, see McMillan \& Chakroborty, 2016). Second, and echoed by Renne, Tolford, Hamidi, and Ewing (2016), the housing costs included in the LAI have both temporal and spatial resolution issues and do not reflect the cost of entry for homeowners (personal communication, September 27, 2016).

To this, scholars have added concern regarding racial disparities. When other factors are held constant, Acevedo-Garcia, McArdle, Hardy, Dillman, Reece, Crisan, Norris, and Osypuk (2016) find racial disparities in opportunity still emerge in data covering education, health and environment, and social and economic opportunity. Transportation costs carry racial differences. Renne et al. (2016) find higher transportation costs in majority African American neighborhoods, perhaps, they speculate, due to characteristics of the vehicle fleet owned. African American neighborhoods also display lower walkability (Koschinsky \& Talen, 2016), which could decrease access to opportunities or require higher-cost transportation alternatives. Relatedly, numerous scholars mention difficulties in use or interpretation stemming from the household types used in the LAI research design, as results are difficult or impossible to modify to reflect actual populations (Nguyen, Webb, Rohe, \& Noria, 2016; Tighe \& Ganning, 2016).

Finally, several scholars who have used the LAI in research note concern regarding the margin of error (MOE) in American Community Survey (ACS) data, especially at the block group level (Acevedo-Garcia et al., 2016; Haas, Newmark, \& Morrison, 2016; Tighe \& Ganning, 2016; Walter \& Wang, 2016). With the exception of Haas et al. (2016), external review of the LAI on the grounds of statistical reliability or validity has gone no further than this. As this manuscript shows, though MOE does present a considerable challenge for the LAI as a whole, other considerations warrant discussion as well.

\subsubsection{A Conceptual Overview}

HUD’s LAI aims to provide "the public with reliable, user-friendly data and resources on combined housing and transportation costs to help consumers, policymakers, and developers make more informed decisions about where to live, work, and invest” (HUD n.d.-b). At the time of this writing, the portal uses data primarily from the 2008-2012 five-year American Community Survey and the 2010 Census LODES database. The portal provides two tools: one giving housing and transportation costs households might expect to pay in a given location, and one that guides a user through prompts to calculate their costs. This section provides a conceptual overview of each tool, though briefly, as the LAI website provides this information publicly.

\subsubsection{The index}

The index gives the estimated percentage of income and dollar amount spent on housing and transportation costs for eight household types. The online version presents this data at the block 
group geography; the tabular data available for download provide estimates at various geographic levels ${ }^{1}$. In addition to the housing and transportation cost estimates, the online tool provides an estimate of annual vehicle miles traveled, the number of annual transit trips taken, and the number of vehicles owned. The online user must select from eight household types as they are given and cannot change any of the selected type's defining characteristics, which are various combinations of income level, household size, and number of commuters. The user can pan and zoom on a built-in map to their target neighborhood. The LAI technical documentation claims the types "are not intended to match the characteristics of any particular family. Rather, they were selected to meet the needs of a variety of users, including consumers, planning agencies, real estate professionals, and housing counselors” (HUD, n.d.-c, p. 26).

Directly because users cannot adjust the estimates to reflect a higher or lower income, or more or fewer commuters, the index should be used to gauge relative, not absolute, affordability. From a technical perspective, this challenge arises from the index's use of structural equation modeling (SEM). In an SEM, the variables, both exogenous (similar to independent variables in traditional regression) and endogenous variables (similar to dependent variables in traditional regression) are inter-related in multiple and complex ways. The multiple and inter-related nature of the variables renders impossible any efforts to guess how much changes in any one variable might influence total costs or affordability. For example, in the LAI's SEM, automobile ownership for renters precipitates from a function of 12 exogenous variables and two endogenous variables, which are themselves the products of 11 and 13 other variables respectively. How could a potential new resident gauge how much neighborhood automobile ownership stems from built environment influences versus socioeconomic ones (the SEM includes both)?

Both practitioners and individual users must then emphasize that LAI affordability estimates are intended to reflect typical costs for household types within block groups. This suggested terminology - "typical costs"-reflects that the LAI does not actually provide average costs. This issue is taken up in the technical considerations section.

Stylistically, the online index does not break down transportation costs into those incurred via automobile and those incurred via public transit. Thus, users cannot reasonably estimate a difference between the modeled values and their own actual costs by manually adjusting transit costs, for instance, based on their own known behavior. Similarly, the index does not make allowances for unusual mortgage or home financing situations. The LAI's second tool, the online calculator, better serves users who desire such a level of accuracy.

As the index does not permit manipulation of estimated costs to reflect edits to the household types, it bears noting that in virtually all cases the index will not represent actual household situations. Even if a household is reasonably well-represented by a household type, the index estimates automobile ownership as a continuous (e.g., 1.7 cars owned) rather than discrete variable (e.g., 2 cars owned), with no information regarding the additional cost incurred by owning another 0.3 cars. Finally, the eight household types do not attempt to cover all situations. For example, no household type accommodates a four-person household with two commuters

\footnotetext{
${ }^{1}$ In the hierarchy of U.S. Bureau of the Census geographies, Census blocks make up block groups, block groups make up Census tracts, and Census tracts make up counties. Census tracts are delineated to capture, ideally, about 4,000 people, although they range in size from about 1,200 to about 8,000 people.
} 
who together earn less than the regional median income. Nor are telecommuters well represented.

To summarize, the LAI represents typical housing and transportation costs at the block group level (or other geographies using the tabular, downloadable data) for prototypical but unobservable households. Users should not modify the LAI estimates in an effort to tailor the household types to individual circumstances. Implicitly, then, the index finds its highest use as either of two tools: 1) an estimate of relative locational costs for households considering relocation, or 2) a resource for analyzing regions for researchers with questions specific to different socioeconomically-defined household groups, such as single parent households, the elderly, or young professionals. The LAI's usefulness for practitioners is less clear, because the index does not reflect the situation of actual neighborhood residents, nor can its output be easily modified to understand the influence of various characteristics.

\subsubsection{The calculator}

The second tool caters to households who have reasonable estimates of their average monthly expenditures and desire tailored estimates of housing and transportation costs they might incur in a given location. The calculator appears to be a series of straightforward calculations based solely on user input. If a user lacks an estimate for a given expense-say, monthly public transportation costs - the calculator suggests the estimate produced by the LAI. Here, however, the LAI technical documentation provides little information, saying only that the calculator "takes advantage of the SEM using the progression of choices made by the user" (HUD, n.d.-c, p. 27).

The technical documentation implies that the calculator's suggested values come from the SEM, with no information on how this is accomplished. In a test of various fictional households in cities, the calculator's suggested values do not match the costs estimated by the index for any of the eight household types. Nor is it clear whether or how the SEM might instantaneously run and produce estimates for user-inputted household characteristics. Nor has HUD provided coefficients which researchers could use to estimate costs for households not conforming to the eight defined household types. The suggested housing costs also mismatch with published figures from the Census Bureau’s American Community Survey.

On one hand, if reliable, the calculator's estimates vastly enhance the tool's usefulness for households by providing estimates more tailored than those the index can provide. At the same time, for practitioners and researchers, this tool brings limited utility absent more information regarding the production of its estimated values for user-generated household profiles.

To conclude this conceptual overview, one aspect of the LAI evinced more questions than any other at a recent Location Affordability Round Table session held during the Association of Collegiate Schools of Planning conference in November 2016: For whom does the index exist? The questions asked mirror the narrative presented here. The eight pre-set household types impose unrealistic assumptions on neighborhoods-assumptions that, if held, would drastically 
and swiftly change the location of opportunities and costs. If, for instance, all of East Cleveland were suddenly inhabited by dual-professional households, a growth in the number of commercial establishments would quickly follow. Moreover, most index users have difficulty finding their household circumstance in the eight pre-set types. Language introducing the calculator might clarify its intended uses and audience.

\subsection{RESEARCH OBJECTIVES}

While the overall research project has four research questions, this chapter covers just one. Does the existing LAI data accurately estimate housing and transportation costs for households in declining neighborhoods in shrinking cities?

\subsection{TECHNICAL CONSIDERATIONS}

The index presents affordability information for housing and transportation. The housing estimates emerge from an SEM built from Census ACS and LODES data, and the householdlevel characteristics of the eight prototypical types (size, number of commuters, and income level). For transportation costs, part of the LAI estimates comes from the SEM, while part stems from an OLS regression using the SEM outputs as inputs, along with Census data inputs. This technical overview begins with concerns relating to data reliability, variable construction, and aggregation for data used in both the SEM and OLS portions of LAI estimation. Following, technical considerations relating to the SEM are addressed and a re-estimation presented.

\subsubsection{Data reliability}

HUD constructs the majority of its variables from ACS 2008-2012 five-year data at the block group level, using many transformations both to create new variables and aggregate to larger levels of geography. ACS critics have long pointed to margin of error issues. These issues stem from sample sizes and tend to be more problematic for small geographic levels such as the block group and Census tract levels. An evaluation of the reliability in the underlying data thus sheds light on the reliability of LAI variables.

The Bureau of the Census publishes ACS estimates alongside each variable's margin of error (MOE). The Coefficient of Variation (CV; Equation 1, using a 90\% Confidence Interval) quantifies the reliability of an estimate based on both the estimate and the MOE. After converting $\mathrm{CV}$ values to ordinal groups researchers can classify observations within datasets as having high ( $\mathrm{CV}=<12.0)$, medium $(12.0<\mathrm{CV}=<40.0)$, or low $(\mathrm{CV}>40.0)$ reliability (Esri, 2014). Table 1.1 summarizes the analysis of reliability for the LAI variables.

$$
C V=\frac{\frac{M O E}{1.645}}{\text { ESTIMATE }} \times 100
$$




\section{Medium to poor reliability variables and tenure}

Across the board, a greater proportion of observations have high reliability among owneroccupied households than among renter-occupied households (Tables 1.1 and 1.2). This is more pronounced at the block group level (Table 1.1). At this level, medium reliability is the modal category for renter households for most variables. For some variables, few block groups have high reliability. Esri labels medium reliability data as “use with caution” (2014, p. 6). However, exercising caution requires an understanding of the LAI's underlying structure.

For example, that the LAI models four of its six endogenous variables using fraction rental units as an input. At the block group level, $46 \%$ of block groups have medium reliability for total households and $62 \%$ for number of renter households. Ohio block groups are modally moderately reliable for estimates of the percentage of single family detached dwelling units, as well as for the number of vehicles available. These variables collectively enter the SEM seven times.

Across all variables, Table 1.2 shows improved data reliability when measured at the Census tract level. This finding contributes directly to one recommendation of this manuscript: The LAI should be recreated and presented at the tract level rather than the block group level. In an ideal case, a block group-level LAI would be more useful since between-block group variation could be captured. Unfortunately, the available data's reliability metrics support a move to the larger Census tract geography, which is still considered a small geography for most policy-oriented datasets. Additionally, Table 1.2 includes several variables that exist only at the tract-level, although they are used in the block group-level LAI models-a practice widely discouraged in quantitative methodologies. This further bolsters the recommendation to shift to a Census tractlevel presentation of the LAI, eschewing the block group-level database.

\section{Data too unreliable for ethical use}

Reliability metrics for the Journey to Work (JTW) data on transit use warrant jettisoning these data altogether (Table 1.2). Similarly, in very few cases statewide can the number of commuters be reliably distinguished from the number of workers. Realistically, removing the transit use data brings far-reaching consequences. At a high level, it requires a replacement estimation methodology be designed and implemented for estimating annual transit trips-an important data point for consumers. Absent this, auto-based costs would replace transportation costs in the LAI. For the Cleveland RTA system area this would overlook approximately $\$ 48,614,000$ in consumer expenditures in 2010 (Rogoff, 2011). Relatedly, HUD undertook a significant effort to estimate MSA-based total transit expenditures in cases where multiple transit authorities serve a region, but unfortunately this information is not provided in the LAI database, making the transit-based costs very difficult to replicate anyway. Beyond the LAI, transit use data used in the LAI is leveraged for the Affirmatively Furthering Fair Housing (AFFH) Assessment Tool, an important tool for fair housing policy implementation.

Given the importance of transit data for place-based housing and community development practice and policy, priority should be given to making the data reliable. The LAI could be improved by incorporating transit supply data, which require considerable data and processing 
demands. The temptation should be avoided to convert regional fare receipts to household expenditure simply by weighting tracts by number of households. In low income neighborhoods in Cleveland and East Cleveland, for instance, the LAI auto cost model's estimated costs of owning a vehicle are cost-prohibitive for many households. Access to employment and other opportunities for these populations thus disproportionately requires access to and use of public transportation, which would be underestimated in a household-weighted distribution of transit expenditures. The situation of using the LAI for shrinking cities like Cleveland, or the AFFH for virtually any setting, would not be markedly improved by such a household-weighted approach. 
Table 1.1: Reliability of LAI SEM inputs at block group level

\begin{tabular}{|c|c|c|c|c|c|c|c|c|c|c|}
\hline & $\begin{array}{l}\text { ACS } \\
\text { Table }\end{array}$ & $\% \mathrm{H}$ & ligh Relial & ility & $\% \mathrm{Me}$ & dium $\mathbf{R e}$ & ability & & Low Relia & bility \\
\hline & & Total & Owners & Renters & Total & Owners & Renters & Total & Owners & Renters \\
\hline $\begin{array}{l}\text { Fraction of rental } \\
\text { units } \\
=\text { Renter- } \\
\text { occupied/Total } \\
\text { households }\end{array}$ & B25003 & $54.1 \%$ & & $2.3 \%$ & $45.8 \%$ & & $62.0 \%$ & $0.2 \%$ & & $35.7 \%$ \\
\hline $\begin{array}{l}\text { Fraction of SF } \\
\text { detached units }\end{array}$ & B25024 & $36.9 \%$ & & & $59.7 \%$ & & & $3.4 \%$ & & \\
\hline $\begin{array}{l}\text { Number of rooms in } \\
\mathrm{OO} \mathrm{HU}\end{array}$ & B25021 & & 91.9\% & $61.9 \%$ & & $7.8 \%$ & $33.2 \%$ & & $0.3 \%$ & $4.9 \%$ \\
\hline Avg HH size & B25010 & & $65.1 \%$ & $21.1 \%$ & & $34.4 \%$ & $76.1 \%$ & & $0.4 \%$ & $2.8 \%$ \\
\hline $\begin{array}{l}\text { Average commuters } \\
\text { per HH } \\
\quad \text { Population in } \mathrm{HH} \\
\text { (used to scale } \\
\text { variable) }\end{array}$ & B11002 & $32.8 \%$ & & & $66.8 \%$ & & & $0.4 \%$ & & \\
\hline $\begin{array}{l}\text { Median selected } \\
\text { monthly owner } \\
\text { costs }\end{array}$ & B25088 & & $65.8 \%$ & & & $31.2 \%$ & & & $3.1 \%$ & \\
\hline Median gross rent & B25064 & & & $46.8 \%$ & & & $42.1 \%$ & & & $11.1 \%$ \\
\hline $\begin{array}{l}\text { Autos per } \mathrm{HH} \\
\text { Aggregate } \\
\text { number vehicles } \\
\text { Households }\end{array}$ & $\begin{array}{l}\text { B25046 } \\
\text { B25003 }\end{array}$ & & $\begin{array}{l}17.8 \% \\
32.5 \%\end{array}$ & $\begin{array}{l}0.6 \% \\
2.3 \%\end{array}$ & & $\begin{array}{l}76.0 \% \\
63.3 \%\end{array}$ & $\begin{array}{l}56.0 \% \\
62.0 \%\end{array}$ & & $\begin{array}{l}6.2 \% \\
4.2 \%\end{array}$ & $\begin{array}{l}43.4 \% \\
35.7 \%\end{array}$ \\
\hline
\end{tabular}


Table 1.2: Reliability of LAI SEM inputs at the Census tract level

\begin{tabular}{|c|c|c|c|c|c|c|c|c|c|c|}
\hline \multirow[b]{2}{*}{ Census tracts } & \multirow[t]{2}{*}{$\begin{array}{l}\text { ACS } \\
\text { Table }\end{array}$} & \multicolumn{3}{|c|}{ \% High Reliability } & \multicolumn{3}{|c|}{ \% Medium Reliability } & \multicolumn{3}{|c|}{ \% Low Reliability } \\
\hline & & Total & Owners & Renters & Total & Owners & Renters & Total & Owners & Renters \\
\hline Fraction of rental units & B25003 & $98.9 \%$ & & $27.4 \%$ & $1.0 \%$ & & $68.6 \%$ & $0.2 \%$ & & $4.0 \%$ \\
\hline $\begin{array}{l}\text { Fraction of SF } \\
\text { detached units }\end{array}$ & B25024 & $89.4 \%$ & & & $9.4 \%$ & & & $1.2 \%$ & & \\
\hline $\begin{array}{l}\text { Number of rooms in } \\
\mathrm{OO} \mathrm{HU}\end{array}$ & B25021 & & $98.2 \%$ & $86.3 \%$ & & $1.7 \%$ & $13.0 \%$ & & $0.1 \%$ & $0.7 \%$ \\
\hline Median HH income* & B25119 & & $66.6 \%$ & $20.8 \%$ & & $30.4 \%$ & $64.5 \%$ & & $3.0 \%$ & $14.7 \%$ \\
\hline Avg HH size & B25010 & & $91.8 \%$ & $61.9 \%$ & & $8.1 \%$ & $37.8 \%$ & & $0.1 \%$ & $0.3 \%$ \\
\hline $\begin{array}{l}\text { Average commuters } \\
\text { per HH } \\
\text { Workers* } \\
\text { Workers who do not } \\
\text { commute* } \\
\text { Population in HH } \\
\text { (used to scale } \\
\text { variable) }\end{array}$ & $\begin{array}{l}\text { B08137 } \\
\text { B08137 } \\
\text { B11002 }\end{array}$ & $96.4 \%$ & $\begin{array}{l}64.8 \% \\
0.0 \%\end{array}$ & $\begin{array}{l}3.3 \% \\
0.0 \%\end{array}$ & $3.4 \%$ & $33.0 \%$ & $86.1 \%$ & $0.2 \%$ & $2.2 \%$ & $10.6 \%$ \\
\hline $\begin{array}{l}\text { Median selected } \\
\text { monthly owner costs }\end{array}$ & B25088 & & $90.9 \%$ & & & $8.3 \%$ & & & $0.7 \%$ & \\
\hline Median gross rent & B25064 & & & $71.3 \%$ & & & $25.9 \%$ & & & $2.8 \%$ \\
\hline $\begin{array}{l}\text { Autos per } \mathrm{HH} \\
\text { Aggregate number } \\
\text { vehicles } \\
\text { Households }\end{array}$ & $\begin{array}{l}\text { B25046 } \\
\text { B25003 }\end{array}$ & & $\begin{array}{l}76.8 \% \\
83.6 \%\end{array}$ & $\begin{array}{c}6.4 \% \\
27.4 \% \\
\end{array}$ & & $\begin{array}{l}21.9 \% \\
15.4 \%\end{array}$ & $\begin{array}{l}87.3 \% \\
68.6 \% \\
\end{array}$ & & $\begin{array}{l}1.3 \% \\
1.1 \%\end{array}$ & $\begin{array}{l}6.3 \% \\
4.0 \% \\
\end{array}$ \\
\hline $\begin{array}{l}\text { \% transit JTW } \\
\text { Workers* } \\
\text { Means of } \\
\text { transportation: } \\
\text { Transit* }\end{array}$ & B08137 & & $64.8 \%$ & $3.3 \%$ & & $33.0 \%$ & $86.1 \%$ & & $2.2 \%$ & $10.6 \%$ \\
\hline
\end{tabular}





\subsection{VARIABLE CONSTRUCTION}

As is common, several variables necessary to produce both the SEM and the automobile cost estimates are constructed from other variables or represent calculations done on spatial data sets. This section presents reliability and validity considerations relating to variable construction and aggregation.

\subsubsection{Representative reliability in employment densities}

The variables for job density and retail job density purport to measure the density of nearby jobs. However, the LAI uses one of three distinct rules for drawing the polygons in which proximate jobs are counted, depending, effectively, on the size and shape of the block group. If the block group rests entirely inside the half mile buffer extending from its population-weighted centroid, the buffer area is used. If the buffer area and the block group boundary are "about the same" (HUD, n.d.-c, p. 16), their union area is used. If the buffer falls entirely within the block group, the block group polygon is used. The employment density variables (total employment and retail employment) therefore face two challenges: representative reliability and reproducibility.

Representative reliability asks whether a measure produces consistent results across social groups-in this case, residents of (sometimes) more and less dense block groups. In this example, residents of high density block groups only access jobs within a half mile buffer, while residents of lower density block groups access jobs within a potentially larger area. Residents of medium density block groups, or, possibly, block groups of any density drawn in irregular geometry such as oblong rectangles, access jobs within less than a half mile buffer. There is no evidence that this approach provides representative reliability. The given technical documentation also provides insufficient information to enable a researcher to replicate the variable, although some information could be gleaned from the code base. HUD is aware of this issue and is addressing it through program updates (personal communication, September 27, 2016).

Beyond this representative reliability issue, this variable also introduces a measurement reliability concern. The LODES data used to construct these density variables (as well as median commute distance, discussed below) represents 2010 — the target year of the whole LAI. However, as has been widely documented by the Census Bureau, it is methodologically indefensible to interpret 2008-2012 five-year data as representing roughly 2010.

\subsubsection{Aggregation}

The LAI Data Dictionary (HUD, n.d.-d) instructs users interested in geographies larger than block groups to aggregate by weighting block groups according to the number of households. Leading the way, HUD provides most of the input variables needed to estimate the LAI aggregated to the tract level using the household weighting scheme. HUD also provides the LAI itself at the tract level, apparently also by weighting the block group-level estimates, although 
this is not clear. For some input variables this approach yields results matching the Census tractlevel data published by the Bureau of the Census. However, for other variables this aggregation method poses one of two challenges: 1) using households as a weight might be appropriate, but weighting data representing medians introduces unnecessary error, or; 2) households represent an inappropriate variable for weighting.

\subsubsection{Creating a weighted average from data representing medians}

The LAI uses LODES data to find the median distance commuted. It accomplishes this by creating a table with block of origin, block of work location, straight-line distance between the two $^{2}$, and commuter flow, then sorting block-block pairs by block group of origin and distance traveled, and identifying the median commuter at the block group level. Mathematically speaking, taking the household-weighted mean of a group of block group medians will not yield the median at the Census tract level. At the mean, estimating the median commute distance via the household-weighting strategy (as recommended by the LAI) yields a value of 9.245 miles for Ohio Census tracts. Recalculating the median by replicating the LAI's process with LODES data yields an average median of 8.480 miles. Thus, at the mean, the LAI underestimates the median by 1.11 miles_-an added $13.1 \%$ error.

As is the case for the variables assessed in the next sub-section, added error introduces two problems. First, it leaves opportunity for heteroscedasticity to enter the estimates, which the LAI either did not encounter at the block group level or did not mention in its technical documentation. While heteroscedasticity may appear for other variables upon aggregation, a Breusch-Pagan test on a bivariate OLS regression (household-weighted and recalculated median commute distance) is negative, meaning that the error does not significantly vary across values of the variable. Moreover, the correlation between the household-weighted median and the newly calculated median is linear and high (0.96), suggesting that household-weighted commute distance might serve as a reasonable proxy for median commute distance.

The second issue is that it is unclear if the LAI's underlying models can or should be recreated at the tract level without more information than is currently available. While this logic applies to multiple parts of the LAI construction, the most straightforward illustration rests in the estimation of VMT. Transportation costs consist of automobile costs and transit costs.

Automobile costs consist of the number owned and miles traveled, both of which are calculated based on a range of input variables. The LAI documentation describes the regression-based estimation method for VMT and provides the coefficients. Those coefficients, calibrated for the block group model, will not adequately accommodate the downward bias inserted into the median commute data via household-weighting to the tract level. In other words, the householdweighted estimates would provide a reasonable instrumental or proxy variable for actual commuting distance, if the model's partial coefficients were not already fixed based on non-

\footnotetext{
${ }^{2}$ To improve the data for this manuscript, a network-based distance calculation was attempted. The computational requirements necessary for the state of Ohio alone were insurmountable. As such, the straight-line approach is necessary, if flawed.
} 
instrumented values. Also, the model cannot be re-estimated because it was calibrated using odometer data from Illinois which is not publicly available. Finally, regardless of the biased commute distance variable, modifiable areal unit problem may invalidate the block-group model's coefficients for application on tract-level data.

\subsubsection{Using a weighting scheme misaligned with variable definition}

In a few cases, weighting by number of households to aggregate uses the wrong variable, because the variables use land area as their denominator. This weighting issue appears in calculating household density, block density, retail density, local jobs density, and employment access. Prior to re-estimation, one would hypothesize that weighting by households rather than basing density calculations on area would logically lead to over-estimates of employment density for retail jobs and for all jobs. Consider the hypothetical case presented in Table 1.3.

Table 1.3. Hypothetical case used to illustrate inappropriate aggregation method

\begin{tabular}{|l|l|l|l|l|l|}
\hline $\begin{array}{l}\text { Block } \\
\text { Group \# }\end{array}$ & Jobs & Households & $\begin{array}{l}\text { Area } \\
\text { (acres) }\end{array}$ & $\begin{array}{l}\text { Density with HH- } \\
\text { weighting scheme }\end{array}$ & $\begin{array}{l}\text { Density with Area- } \\
\text { based weighting }\end{array}$ \\
\hline 1 & 500 & 750 & 50 & $\begin{array}{l}(750 *(500 / 50))+ \\
(750 *(500 / 25))= \\
15.0\end{array}$ & $\begin{array}{l}(500+500) /(50+25) \\
=13.3\end{array}$ \\
\hline 2 & 500 & 750 & 25 & & \\
\hline
\end{tabular}

Table 1.4 shows, for Ohio Census tracts, the difference in estimates produced using the household weighting scheme versus a recalculation based on land area. Notably, jobs density and retail jobs density recalculations also introduce uniform buffer areas, as discussed previously; Differences in those variables' estimates thus stem from both the weighting scheme and the research design. As hypothesized, the household-weighted figures over-estimate all but the employment access variable, the calculation of which is more complicated than simple density. The household-weighting scheme introduces additional error ranging from $4.5 \%$ in the employment access index to $114 \%$ in retail density. As a slight aside, HUD provides the block group level data necessary to calculate the household-weighted Census tract variables. HUD does not, however, provide the data necessary to reconstruct LODES-based variables (retail jobs/acre, job/acre, and employment access), although it is publicly available elsewhere.

Table 1.4. Aggregating area-based variables according to household weighting introduces unnecessary error

\begin{tabular}{|l|c|c|c|}
\hline Variable & $\begin{array}{c}\text { Household- } \\
\text { weighted Estimate }\end{array}$ & $\begin{array}{c}\text { Recalculated } \\
\text { Estimate }\end{array}$ & $\begin{array}{c}\text { Added \% } \\
\text { Error }\end{array}$ \\
\hline Household density & 2.0764 & 1.72 & 20.7 \\
\hline Block density & 0.0889 & 0.0773 & 15.1 \\
\hline Retail jobs per acre & 0.17704 & 0.08255 & 114.5 \\
\hline Jobs per acre & 2.0163 & .955646 & 111.0 \\
\hline Employment access & 17,743 & 18,575 & 4.5 \\
\hline
\end{tabular}




\subsection{THE LAI STRUCTURAL EQUATION MODEL}

An SEM sits at the heart of the LAI methodology. The method is well-paired to the reality that socioeconomic characteristics, features of the built environment, and resulting costs have complex interactions. However, an effort to reproduce and improve the SEM reveals methodological concerns pertaining to model logic, diagnostics, and reproducibility.

SEMs accommodate inter-related variables, and as such require the researcher to identify and define those relationships. In the LAI documentation (HUD, n.d.-c, p. 6), its architects provide a table elucidating the hypothesized relationships between variables. Only some of those hypothesized relationships find backing in existing theory or empirical research. Whether this constitutes a flaw in research design may be up to the beholder. On one hand, as Haas et al. note, "the model was designed to maximize predictive accuracy—not to best explain the underlying phenomenon - and therefore includes some highly collinear variables that complicate interpretation” (2016, p. 576). On the other hand, the users' manual for the AMOS SEM program (SPSS's program) states, "Do not make changes based on [modification index] and [expected predicted change] unless they make theoretical sense” (Munger, 2002; see also Garson, 2015).

The model's technical documentation defends model fit based on three diagnostic tests: Root Mean Square Error of Approximation (RMSEA), Comparative Fit Index (CFI), and Standardized Root Mean Square Residual (SRMR). While the LAI's SEM does fare well on these metrics, its architects omit the chi-square, a standard diagnostic for SEM. As a rule of thumb, an SEM's chisquare should be less than 10 . The chi-square for the LAI is not reported. As elaborated on below, efforts to re-create the LAI for Ohio yielded chi-square values ranging from 300 into the thousands.

\subsection{THE IMPACT OF REVISIONS ON LAI ESTIMATE OUTCOMES}

To summarize, the recommendations for modification to the LAI include: shift from the block group level to the Census tract level to improve reliability; recalculate the area-based and median-based variables rather than weighting by number of households; and make minor modifications to enhance the SEM fit. To estimate the effect of these issues on the LAI's estimates, the SEM was re-run for Household Type 1, producing new estimates of location affordability for the median household type.

\subsection{METHODS}

Table 1.5 summarizes the variables used in the SEM, including data sources and any methodological notes on deviations from the original HUD methods. In some cases, the variables resemble those immediately downloadable from the U.S. Bureau of the Census. For others, such as the median commute distance, R-based programming (the scripts for which are available from the author upon request) was used to calculate the variables. 
Table 1.5: Summary of methods

\begin{tabular}{|c|c|c|c|}
\hline Variable & $\begin{array}{l}\text { Variable } \\
\text { Symbol }\end{array}$ & $\begin{array}{l}\text { Data } \\
\text { Source } \\
\text { (ACS } \\
\text { unless } \\
\text { otherwise } \\
\text { noted) }\end{array}$ & Methods Notes \\
\hline $\begin{array}{l}\text { Median rooms per } \\
\text { household unit for renters }\end{array}$ & Medroomsrent & & $\begin{array}{l}\text { Used data published at Census } \\
\text { tract level. }\end{array}$ \\
\hline Job density & JobDensity & $\begin{array}{l}\text { Census } \\
\text { LEHD }\end{array}$ & $\begin{array}{l}\text { R code available upon request. } \\
\text { Recreated HUD's original } \\
\text { methodology at the Census tract } \\
\text { level. }\end{array}$ \\
\hline $\begin{array}{l}\text { Commuters per } \\
\text { household-renters }\end{array}$ & commHHRent & & $\begin{array}{l}\text { Used data published at Census } \\
\text { tract level. }\end{array}$ \\
\hline Household size-renters & hhsz_rent & & $\begin{array}{l}\text { Used data published at Census } \\
\text { tract level. }\end{array}$ \\
\hline $\begin{array}{l}\text { Median commute } \\
\text { distance }\end{array}$ & med_dist & $\begin{array}{l}\text { Census } \\
\text { LODES }\end{array}$ & $\begin{array}{l}\text { R code available upon request. } \\
\text { Recreated HUD’s original } \\
\text { methodology for the Census tract } \\
\text { level by organizing all origin- } \\
\text { destination flows by distance, } \\
\text { finding the median commuter, } \\
\text { and recording the distance } \\
\text { commuted for each tract. }\end{array}$ \\
\hline $\begin{array}{l}\text { Area income fraction- } \\
\text { renters }\end{array}$ & inc_frac_rent & & $\begin{array}{l}\text { Used data published at Census } \\
\text { tract level and MSA/county level. }\end{array}$ \\
\hline $\begin{array}{l}\text { Fraction single family } \\
\text { detached dwelling units }\end{array}$ & SF1Det & & $\begin{array}{l}\text { Used data published at Census } \\
\text { tract level. }\end{array}$ \\
\hline $\begin{array}{l}\text { Median number of } \\
\text { rooms—owner-occupied } \\
\text { dwelling units }\end{array}$ & Medroomsown & & $\begin{array}{l}\text { Used data published at Census } \\
\text { tract level. }\end{array}$ \\
\hline Gross household density & GrossHHDen & & $\begin{array}{l}\text { R code available upon request. } \\
\text { Number of households divided by } \\
\text { the land area reported in Census } \\
\text { TIGER/Line files. }\end{array}$ \\
\hline Fraction rental units & FracRental & & $\begin{array}{l}\text { Used data published at Census } \\
\text { tract level. }\end{array}$ \\
\hline Employment access & EmpAccess & $\begin{array}{l}\text { Census } \\
\text { LEHD }\end{array}$ & $\begin{array}{l}\text { R code available upon request. } \\
\text { Recreated HUD’s original } \\
\text { methodology at the Census tract } \\
\text { level. }\end{array}$ \\
\hline $\begin{array}{l}\text { Commuters per } \\
\text { household-owners }\end{array}$ & commHHOwn & & $\begin{array}{l}\text { Used data published at Census } \\
\text { tract level. }\end{array}$ \\
\hline Household size—owners & hhsz_own & & $\begin{array}{l}\text { Used data published at Census } \\
\text { tract level. }\end{array}$ \\
\hline
\end{tabular}




\begin{tabular}{|l|l|l|l|}
\hline $\begin{array}{l}\text { Area median household } \\
\text { income }\end{array}$ & AreaMedInc & $\begin{array}{l}\text { Used data published at MSA or } \\
\text { county level, per the original } \\
\text { HUD methods. }\end{array}$ \\
\hline $\begin{array}{l}\text { Area income fraction_- } \\
\text { owners }\end{array}$ & inc_frac_own & $\begin{array}{l}\text { Used data published at Census } \\
\text { tract level and MSA/county level. }\end{array}$ \\
\hline $\begin{array}{l}\text { Selected monthly owner } \\
\text { costs }\end{array}$ & SMOC & $\begin{array}{l}\text { Used data published at Census } \\
\text { tract level. }\end{array}$ \\
\hline Median rent & MedRent & $\begin{array}{l}\text { Used data published at Census } \\
\text { tract level. }\end{array}$ \\
\hline $\begin{array}{l}\text { Vehicles available per } \\
\text { household_owners }\end{array}$ & VehHHOwn & $\begin{array}{l}\text { Used data published at Census } \\
\text { tract level. }\end{array}$ \\
\hline $\begin{array}{l}\text { Transit used in } \\
\text { commuting_-owners }\end{array}$ & TransitOwn & $\begin{array}{l}\text { Used data published at Census } \\
\text { tract level. }\end{array}$ \\
\hline $\begin{array}{l}\text { Vehicles available per } \\
\text { household_-renters }\end{array}$ & VehHHRent & $\begin{array}{l}\text { Used data published at Census } \\
\text { tract level. }\end{array}$ \\
\hline $\begin{array}{l}\text { Transit used in } \\
\text { commuting_-renters }\end{array}$ & TransitRent & $\begin{array}{l}\text { Used data published at Census } \\
\text { tract level. }\end{array}$ \\
\hline
\end{tabular}

Having assembled the LAI database at the tract level, the AMOS package of SPSS was used to recreate the LAI's SEM using the causal pathways prescribed in the HUD documentation and given in Figure 1.2, with variables constructed as in Table 1.5. The SEM outputs were then input into equations (R script available upon request) estimating housing costs for Household Type 1, the Regional Median Household. As in the LAI Methodology document, precautions were taken to temper extreme estimates.

The results of this estimation-abbreviated "R1" below-were then compared to the tract-level estimates published in the LAI. A second comparison is also presented: one in which Household Type 1 is redefined. Household Type 1 purports to represent the regional median household, but of the three defining characteristics (income, number commuters, and household size), only income reflects the regional median. Thus, in the estimation abbreviated "R2" below, Household Type 1 was altered to use the regional (or county, in non-metropolitan areas) average household size and number of commuters, in addition to using the regional/county median income.

\section{$1.9 \quad$ RESULTS}

The SEM as designed by HUD fares poorly on all three evaluation metrics when run using the revised data at the tract level. The Comparative Fit Index (CFI), which the LAI Data and Methodology document notes should surpass 0.90, instead measures at 0.360 . The Root Mean Square Error of Approximation (RMSEA), which the same document suggests should fall below 0.10 , is estimated instead at 0.232 . The chi-square measures at 25,317.778, where values less than 10 are preferred. That the model diagnostics differ from HUD's published results fails to surprise; HUD executed its model at the block group level with several variables calculated differently. 
The model was modified first based on a causal path diagram designed to reflect theoreticallygrounded relationships between variables. The path diagram was further edited by adding additional covariances and causal arrows to the model based on the Modification Index values. Figure 1.3 presents the resulting path diagram. With these revisions, model diagnostics easily pass the standards given above. The chi-square is 2.640; the CFI equals 1.000, and the RMSEA equals 0.000 . Notably, however, this model has only 10 degrees of freedom. The outputs from this SEM were entered into equations, per the LAI methodology, to produce the R1 estimates. The same SEM model design was used, with the updated household types, to produce the R2 estimates.

The results show notable departures from the LAI published cost and affordability estimates. HUD LAI estimates for Selected Monthly Owner Costs exceed those of R1 by, on average, $5.6 \%$, or $\$ 70$, which corresponds to an additional $1.6 \%$ of household income. The variation between the LAI and R2 estimates is less than 1\%. The difference in the estimate of Median Rent, however, exceeds $20 \%$ when comparing the HUD estimates to either R1 or R2 estimates (Figure 1.1). These differences correspond to $5.0 \%$ and $5.8 \%$ differences, respectively, in cost burden as a percent of household income. In other words, the HUD LAI estimates appear not to be robust, especially in the estimation of median rent; this will impact the conclusions of all analyses drawn from research and policy decisions based on those estimates.

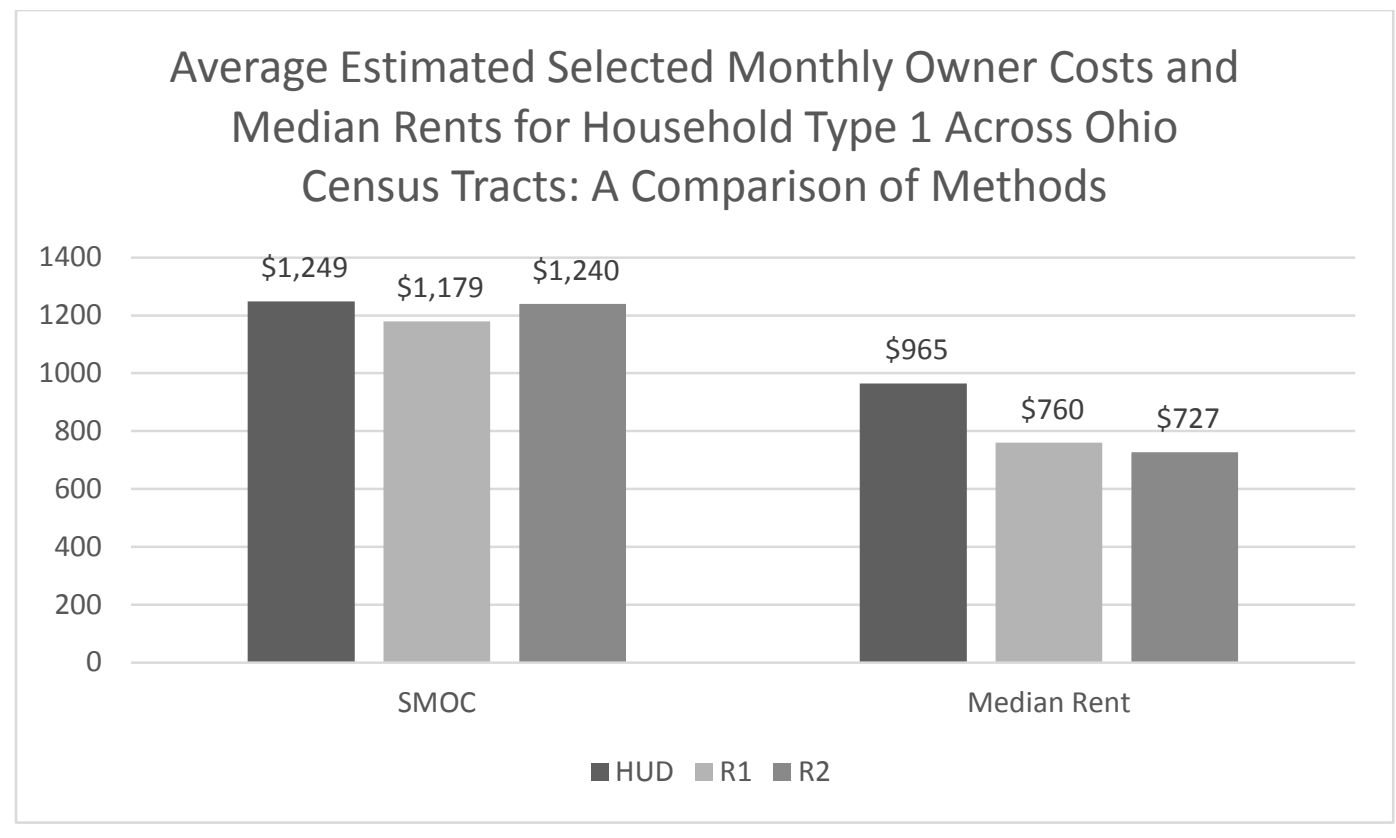

\section{Figure 1.1: Comparison of housing costs}

Moran's I tests for spatial patterning in the estimate differentials (HUD-R1, HUD-R2, and R1$\mathrm{R} 2$, for owners and renters) reveal statistically significant (pseudo-p-value $<0.001$, using queenbased first order weights) positive spatial autocorrelation for all six differentials. This means that high differentials are often found adjacent to other tracts with high differentials, and the inverse 
is also true. While all six differentials showed significant, positive global spatial autocorrelation, tests for local spatial autocorrelation (clusters) show variation. Table 1.6 describes the patterns observed.

Table 1.6: Results of univariate local Moran's tests

\begin{tabular}{|c|c|c|c|}
\hline & & $\begin{array}{c}\text { High-high Cluster } \\
\text { Locations }\end{array}$ & $\begin{array}{c}\text { Low-low-Cluster } \\
\text { Locations }\end{array}$ \\
\hline \multirow{3}{*}{$\sum_{n}^{0}$} & HUD - R1 & $\begin{array}{l}\text { Cleveland, } \\
\text { Columbus, } \\
\text { Cincinnati }\end{array}$ & Southeast Ohio \\
\hline & HUD - R2 & $\begin{array}{l}\text { Cleveland, } \\
\text { Columbus, } \\
\text { Cincinnati }\end{array}$ & Southeast Ohio \\
\hline & R1 - R2 & $\begin{array}{l}\text { Patches throughout } \\
\text { state }\end{array}$ & $\begin{array}{c}\text { Areas surrounding } \\
\text { Cleveland and } \\
\text { Dayton }\end{array}$ \\
\hline \multirow{3}{*}{ 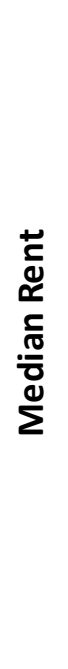 } & HUD - R1 & $\begin{array}{l}\text { Concentrated parts } \\
\text { of the Cincinnati, } \\
\text { Columbus, and } \\
\text { Cleveland suburbs }\end{array}$ & Southeast Ohio \\
\hline & HUD - R2 & $\begin{array}{l}\text { Concentrated parts } \\
\text { of the Cincinnati, } \\
\text { Columbus, and } \\
\text { Cleveland suburbs }\end{array}$ & Southeast Ohio \\
\hline & R1 - R2 & $\begin{array}{l}\text { Wide area around } \\
\text { Dayton and } \\
\text { Cleveland, smaller } \\
\text { extent around } \\
\text { Toledo }\end{array}$ & $\begin{array}{l}\text { Running north- } \\
\text { south in patches } \\
\text { through the center } \\
\text { of the state }\end{array}$ \\
\hline
\end{tabular}

As Table 1.6 shows, the HUD methodology is most likely to overestimate costs in metropolitan areas and either underestimate costs or have low differentials in more rural areas, such as southeast $\mathrm{Ohio}^{3}$. The estimate differentials between methods R1 and R2, which reflect differences in household size and number of commuters, also show urban-rural patterns, but inconsistently. Method R1 shows lower differentials for owner-occupied housing costs in urban areas, but higher differentials for rental costs.

Transportation costs were not re-estimated due to the data limitations noted in this manuscript. Briefly, the OLS coefficients are published for the block group models, but not the Census tract models. The odometer readings from Illinois are not publicly available, which might allow reconstruction of the regression model, making the first concern obsolete. Regardless, this would

\footnotetext{
${ }^{3}$ Relative population density across the state can be seen via this U.S. Census Bureau thematic map: http://www2.census.gov/geo/pdfs/maps-data/maps/thematic/us_popdensity_2010map.pdf
} 
provide only a partial view of transportation costs, as the Census data on transit use among commuters bear margins of error prohibiting use; data on transit supply should be curated for future model implementation.

\subsection{UNDER-THE-HOOD CONCLUSIONS}

The effort on the part of the federal government to illuminate issues of segregation and opportunity and to shift the conversation about affordability to be inclusive of these issues is both commendable and just. There is nothing to be gained in going backwards, away from a location-efficiency view of household affordability.

The LAI attempts to provide such a view of affordability by estimating housing and transportation costs for eight prototypical households at the block group level across the U.S. As shown by this manuscript, using data from the diverse state of Ohio, the LAI appears more robust in estimating housing costs for homeowners than renters. The published LAI likely significantly over-estimates median rents for Household Type 1, and for both owners and renters likely overestimates costs in metropolitan areas and underestimates them or has relatively lower error in rural areas.

For renters and for all transportation cost estimates, some measures need to be taken to shore up reliability and validity issues in the underlying data and metrics, and thus to protect the LAI and its related programs nationally. Some of the issues raised in this manuscript could be resolved relatively easily. HUD could, for instance, publish tract-level data based on the ACS and stop advising users to create the data from household-weighting the block group data, introducing unnecessary error. However, that effort would repair only part of the problem.

Of greater assistance would be a wholesale recalculation at the Census tract level —of the LAI and its subparts, including the vehicle cost model. Three reasons recommend the switch to a tract-level LAI. First, some of the input variables already represent Census tracts, yet are used to support estimates at smaller geographies, which is not methodologically ideal. Second, block group-level data suffer from unacceptable margins of error for both owners and renters in some variables, and present modally medium- or low-reliability data for most variables among renteroccupied households. Using Census tract-level data ameliorates much of this concern, as shown. Third, calculating the index at the tract-level would prevent users from introducing error via inappropriate methods of aggregation, or by using regression coefficients intended for use in block group models.

In addition to changing the underlying data as suggested above, users may benefit from an ancillary database presenting place-based affordability for people currently residing in neighborhoods. Part of such a database can be readily developed from existing ACS data on housing affordability. Estimates of automobile-based affordability could be produced using the regressions and techniques developed for the LAI, but coefficients appropriate for use at the Census tract level need to be produced and provided.

Finally, users deserve a clearer articulation of what questions the existing LAI can addresspending improvements to data reliability as noted above - and those it should not try to address. The conversation about location affordability advances national policy in the U.S. The LAI 
provides an important tool in advancing that conversation and, hopefully, in advancing more equitable and sustainable place-based planning outcomes. Someday those outcomes will be measured, and the location efficiency effort as a whole evaluated. Taking steps proactively to ensure the reliability, validity, and usefulness of the LAI today will ensure that the evaluation of tomorrow focuses on social issues - not technical ones - and productive next steps. 


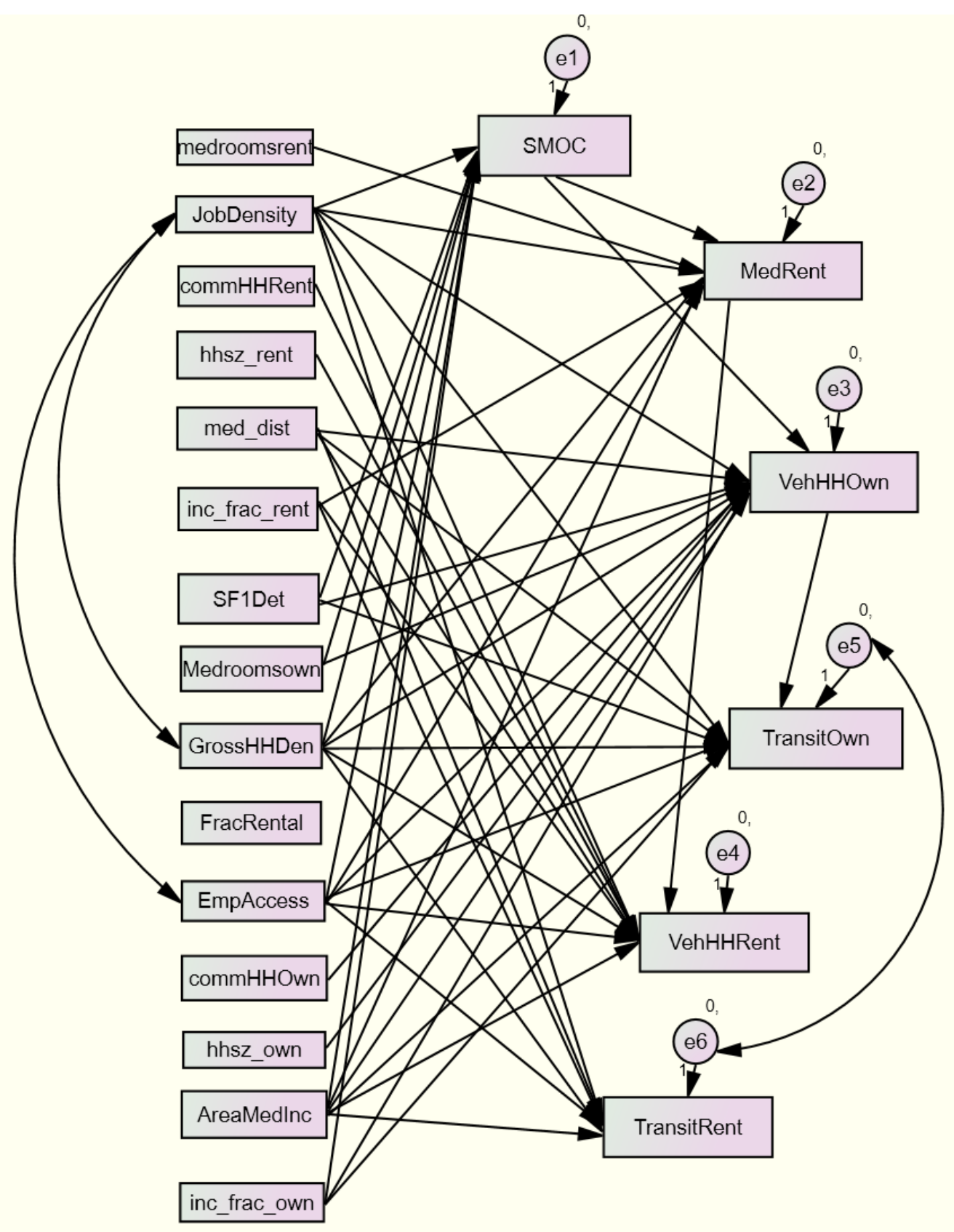

Figure 1.2: HUD LAI path diagram 


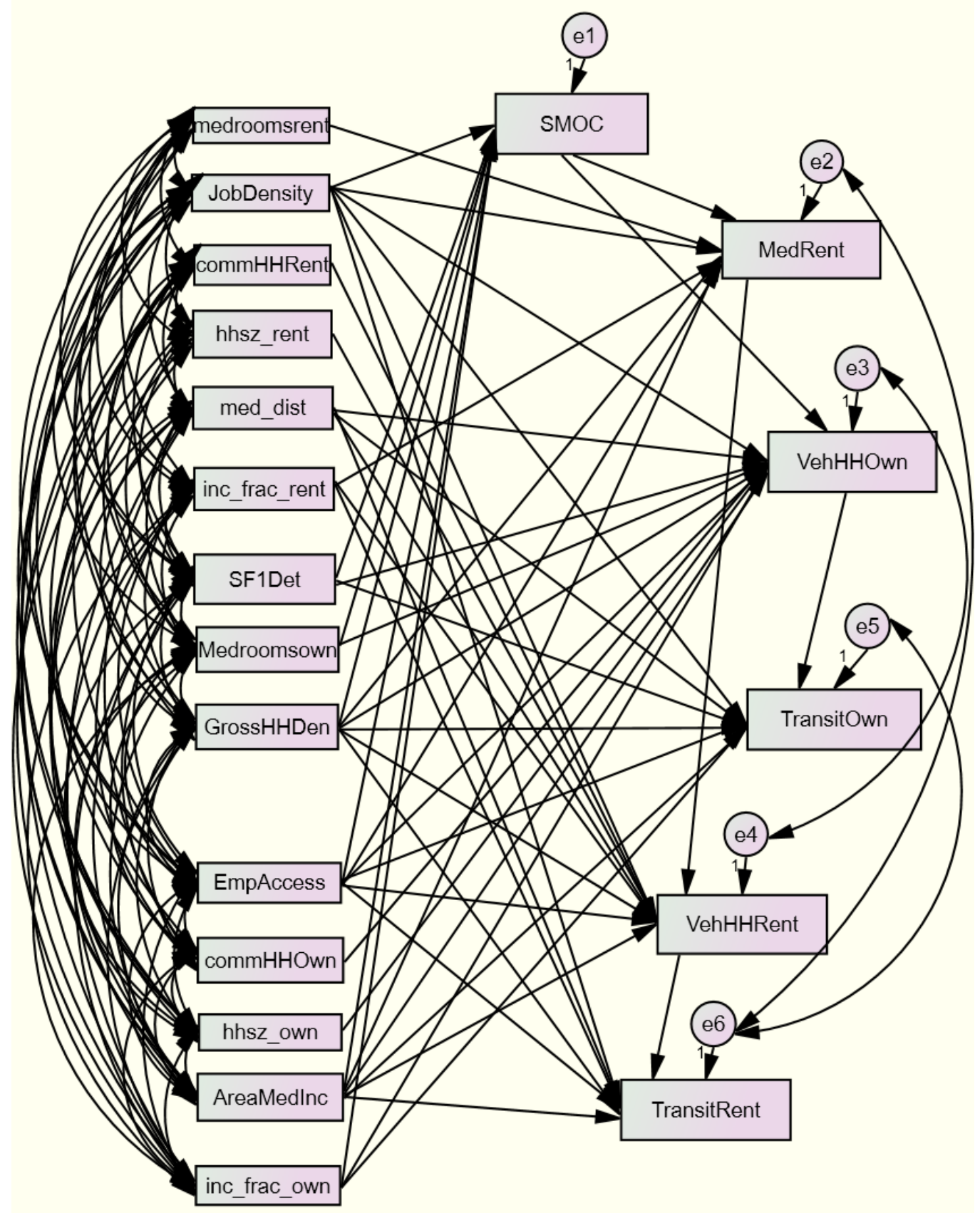

Figure 1.3: Revised path diagram 


\subsection{ON THE GROUND: WHAT DO WE KNOW ABOUT LOCATION AFFORDABILITY IN U.S. SHRINKING CITIES?}

HUD's Location Affordability Index (LAI) portal is used by transportation policymakers and planners across the country to aid in their decision-making. The dataset uses models to estimate what households spend on housing and transportation, and calculates " $\mathrm{H}+\mathrm{T}$ Affordability," the percent of household income spent on these items. However, there is virtually no validation of the data at all, with no studies delving into how accurate the estimates are in "shrinking" or weak-market cities. This study fills this gap by using a resident survey to determine whether the assumptions made in the literature regarding household expenditures and transportation accessibility hold when analyzing cities struggling with population decline. We present results from a household survey in Cleveland, Ohio, a prototypical shrinking city, which focuses on the travel and spending behavior of people living in different types of neighborhoods, focusing primarily on poor households in struggling neighborhoods. We conclude by synthesizing our analyses and providing recommendations for improving the LAI data for shrinking cities, and for informing local transportation policy to improve livability.

\subsection{INTRODUCTION}

Planners, policymakers, and regional scientists have studied how housing and transportation expenses interact for decades (Bogdon \& Can, 1997; Coulton, Leete \& Bania, 1999; Hamidi \& Ewing, 2015; Jain \& Brecher, 2014). Within this work, research has emerged exploring how best to provide access to both affordable housing and affordable transportation for poor households (Acevedo-Garcia, et al., 2016; Lipman, 2006; Pendall et al., 2015; Wachs, 2010). Recent studies suggest that transportation expenditures impose a heavy burden on low-income households (Fan \& Huang, 2011; Sanchez, 2007), and that the poor make budgetary trade-offs when faced with escalating housing or transportation costs (Blumenberg \& Agrawal, 2014; Litman, 2016; Sanchez et al., 2006).

In late 2013, HUD launched the Location Affordability Index (LAI) portal. Their dataset uses models to estimate what households spend on housing and transportation, and calculates " $\mathrm{H}+\mathrm{T}$ Affordability," the percent of household income spent on these items. Whether the model estimates costs for one of the LAI's eight household types or for user-input characteristics (online calculator only), the model assumes all households in the neighborhood are identical, rather than reflecting the characteristics of households who actually live in the given neighborhood. That this complicates interpretation is a known problem (see Chapter 1 of this report), yet the research to date to address that shortcoming has focused only on single case study cities (e.g., Fan \& Huang, 2011). As a result, there is virtually no validation of the data at all, much less for weak market settings. We seek to focus on shrinking, or legacy cities, to determine whether the assumptions made in the literature regarding household expenditures and transportation accessibility hold when analyzing cities struggling with population decline.

Shrinking cities differ from their growing counterparts in a number of ways, particularly in terms of policy approaches and available tools in the areas of housing and transportation (Dewar \& Thomas, 2012; Hoornbeek \& Schwartz, 2009; Mallach, 2010; Tighe \& Ganning, 2016). In terms 
of transportation policy, shrinking cities also face challenges that differ from other metropolitan areas. Public transit depends on adequate population density to function efficiently and equitably (Cervero, 1998). In cities where population and household numbers are declining, the concurrent loss in density poses a particular challenge for regional transit agencies. Furthermore, such cities have experienced significant job loss and economic decline for decades and, more recently, struggle to recover from the Great Recession (Greater Ohio Policy Center, 2016). Galster (2012) demonstrates that in Detroit, outward land consumption far outpaces population growth. For transit agencies, this trend means covering more ground without more money.

Based on these facts, it is unlikely that estimates based on national medians or pre-determined household types would estimate accurate housing or transportation costs and tradeoffs for people living in shrinking cities. We seek to remedy this issue by analyzing the existing literature regarding household transportation and housing affordability as well as examining budgetary tradeoffs made by poor households. We present results from a household survey in Cleveland, Ohio, a prototypical shrinking city, which focuses on the travel and spending behavior of people living in different types of neighborhoods, focusing primarily on poor households in struggling neighborhoods. We conclude by synthesizing our analyses and providing recommendations for improving the LAI data for shrinking cities, and for informing local transportation policy to improve livability.

\subsection{TRANSPORTATION NEEDS OF POOR HOUSEHOLDS AND NEIGHBORHOODS IN SHRINKING CITIES}

While most Americans rely on cars for transportation, the urban poor are often dependent on public transportation. Household transportation expenditures have increased from the sixth largest share (less than 2\%) of household budgets in 1917 to the second largest share in 2000 (Hass et al., 2008). Continuing this trend, housing and transportation costs rose $52 \%$ and 33\% respectively in the largest metropolitan areas from 2000-2010, which is much higher than the household income increase (25\%) over the same period (Hickey et al., 2012). Such increases disproportionately affect very low-income households, who saw their transportation costs rise to approximately 44\% of household income (Hass et al., 2008) — a far cry from the 15\% threshold deemed "affordable" by policymakers and scholars, and a higher percentage than that spent by higher-income households (Hickey et al., 2012).

In any context, increased transit costs result in individuals making tough choices regarding their household-level budgetary choices. Many low-income households cope with transportation costs by reducing purchases of discretionary items and by reducing car maintenance costs by learning to perform those services themselves (Agrawal et al., 2011). However, research to more clearly understand the nature and extent of use of various tradeoffs is quite limited. A number of studies (Agrawal et al., 2011; Fan \& Huang, 2011) conclude that transportation policy should reflect lifecycle-based transportation needs, but neighborhood-level cost estimations seldom take these into account.

Agrawal et al. (2011) discovered how low-income families manage their transportation expenditures given limited resources from 70 face-to-face interviews. Strategies the interviewees were using to lower their transportation costs included: informal income-generating activities, soliciting formal and informal support from others, and other "creative" ways to minimize costs . 
The informal income-generating activities included panhandling, recycling cans, selling merchandise at flea markets, and charging other people for rides or for the use of their car if they have an automobile. Formal support was from government agencies, nonprofit organizations, employers, and landlords, while informal support was from rides with family members or friends. Creative ways to minimize costs included efforts to seek out the cheapest gas, maintaining and repairing vehicles themselves, fare evasion on public transit, or completely depending upon free fare zones. Agrawal et al. (2011) find that low-income households also cope with transportation costs by reducing purchases of discretionary items like cigarettes, meals out, entertainment, and other items.

Finally, transportation costs and cost burdens correspond to more than just household income. Variation in household transportation costs correlates more closely with variations in neighborhood characteristics such as location, built form, or proximity to opportunities than to household characteristics (Haas et al., 2008). Moreover, in all urban contexts, there is significant divergence across neighborhoods within cities (Tighe \& Ganning, 2015). Thus, we would expect not only that low-income populations in shrinking cities have different transportation experiences than those in growing cities, but that those living in different neighborhoods within shrinking cities would as well. The LAI deals with these distinctions in the sense that it includes data on employment accessibility, retail proximity, and other related information. The regional science and economics literature remains under-developed in its understanding of market mechanisms in weak market cities. As such, the LAI does not and cannot predict the impact of accessibility and retail proximity, for example, on housing costs for weak market versus strong market settings.

\subsubsection{Approach}

In our previous research, we analyzed 80 shrinking cities (see Ganning \& Tighe, forthcoming) to determine how location affordability differs across various neighborhoods. Our results suggest that households in declining neighborhoods, as compared to stable or redeveloping neighborhoods, face the greatest $\mathrm{H}+\mathrm{T}$ affordability challenges in shrinking cities, according to LAI data. Furthermore, in declining neighborhoods, virtually all of the additional affordability challenges encountered can be accounted for by differences in transportation affordability rather than housing (Tighe \& Ganning, 2016).

Since there is virtually no research to either validate or suggest bias in the LAI data, and a declining neighborhood in a shrinking city presents both a relatively common yet entirely dissimilar context to the norm, this project sought to evaluate the reliability and validity of the LAI data, and its accuracy in a shrinking city context. Chapter 1 of this report shows that the LAI's underlying data contains serious reliability issues at the block group-level, and a tractlevel LAI is recommended. A reproduction of the index at that level indicates the LAI likely overestimates housing cost and cost burden, but more so among renters, and especially in metropolitan areas. More germane to this chapter, the transportation cost estimates could not be reproduced at all due to data reliability issues that cannot be overcome by shifting geographic levels, and due to insufficient provision of data from HUD.

This study utilizes survey methodology to produce transportation cost estimates for neighborhoods across Cleveland, Ohio, a prototypical shrinking city, as a means of testing the 
accuracy of LAI estimates where quantitative recalibrations from secondary data proved impossible. Following the presentation of survey results, this chapter explores potential alternatives and produces recommendations for policymakers and urban planners to better serve low-income households through transportation policy interventions in shrinking cities. While some of these strategies could be reflected better in the existing LAI model, this research is specific to the very low income, not to shrinking cities, and does not leverage the very recent research finding that residents of declining neighborhoods are sometimes able to access transportation resources in nearby neighborhoods as a coping strategy (Tighe \& Ganning, 2016).

In order to further understand the housing and transportation costs and challenges facing those living in shrinking cities, we implemented a household level survey. In previous work (Tighe \& Ganning, 2016), we identified neighborhood types. To measure change in neighborhoods, we created a Redevelopment Index, which is the average of the standardized values of population change (2000-2010) and employment change (2002-2010) at the block group level. To calculate the population change component of the Index, we apportioned 2000 block-level population data to the 2010 block group boundaries, then calculated population change, and standardized the values to z-scores. The employment change sub-index was calculated using the U.S. Census Bureau's Longitudinal Employer-Household Dynamics (LEHD) program's database. For both variables, the values were standardized into z-scores. The Redevelopment Index is a simple average of the two sub-indices.

Having calculated the Redevelopment Index value for each block group within the city of Cleveland, we then used the Local Indicator of Spatial Association (LISA) tool (with k-nearest weights, where $k=4$, and a confidence level of 95\%) in GeoDa to identify the centers of clusters experiencing low or high index values, or values not statistically significantly low or high. We then designated the cluster centers with low values as "declining" neighborhoods, those with high values as "redeveloping" neighborhoods, and those with insignificant values as "stable" neighborhoods.

Our data consists of 484 households in 11 Cleveland Census tracts, classified as "stable," "redeveloping," or "declining.” Overall, our sample population closely resembled the resident population, based on American Community Survey (ACS) data from the U.S. Bureau of the Census. However, there were a few notable exceptions. In Tract 1187 (Green D, where the color refers to a geographic cluster of surveyed tracts and the letter indicates it as a declining tract), our sample population consisted of considerably more African American households (60\% vs 20\% according to the ACS) and was highly skewed toward renters (88\% vs 38\% according to the Census data) and households earning below $\$ 50,000$ (77\% vs the Census $61 \%$ ). This bias is partially remediated, though, by a bias in the other direction in the second Green D tract (1184) we sampled, where the population included more white households and fewer renter households. In sum, our sample demographics indicate that people responding to our survey are more likely to be African American, poor, and renters than what the Census demonstrates. This could be a result of either sampling error, changes in the demographics of these neighborhoods, or that the incentive offered (the chance to be entered in a drawing for a \$25 gift card) was more appealing to lower-income families.

We received 176 surveys from residents of declining neighborhoods; 150 from those in redeveloping neighborhoods and 157 from those in stable neighborhoods, all generally in the 
northeast section of Cleveland (see Figure 2.1). Our responses represent between 3 and $8 \%$ of households in the selected neighborhoods ${ }^{4}$.

\begin{tabular}{lc} 
Neighborhood Name & ID \\
\hline Bellaire-Puritas & 1 \\
Broadway-Slavic Village & 2 \\
Brooklyn Centre & 3 \\
Buckeye-Shaker Square & 4 \\
Buckeye-Woodhill & 5 \\
Central & 6 \\
Clark-Fulton & 7 \\
Collinwood-Nottingham & 8 \\
Cudell & 9 \\
Cuyahoga Valley & 10 \\
Detroit Shoreway & 11 \\
Downtown & 12 \\
Edgewater & 13 \\
Euclid-Green & 14 \\
Fairfax & 15 \\
Glenville & 16 \\
Goodrich-Kirtland Pk & 17 \\
Hopkins & 18 \\
Hough & 19 \\
Jefferson & 20 \\
Kamm's & 21 \\
Kinsman & 22 \\
Lee-Harvard & 23 \\
Lee-Seville & 24 \\
Mount Pleasant & 25 \\
North Shore Collinwood & 26 \\
Ohio City & 27 \\
Old Brooklyn & 28 \\
Tremont & 29 \\
Union-Miles & 30 \\
University & 31 \\
West Boulevard & 32 \\
St.Clair-Superior & 33 \\
Stockyards & 34 \\
D=Declining & \\
S=Stable & \\
R=Redeveloping & \\
Cleveland neighborhood & \\
shapefile courtesy of NODIS, \\
Levin College of Urban Affairs \\
Cleveland State University & \\
&
\end{tabular}

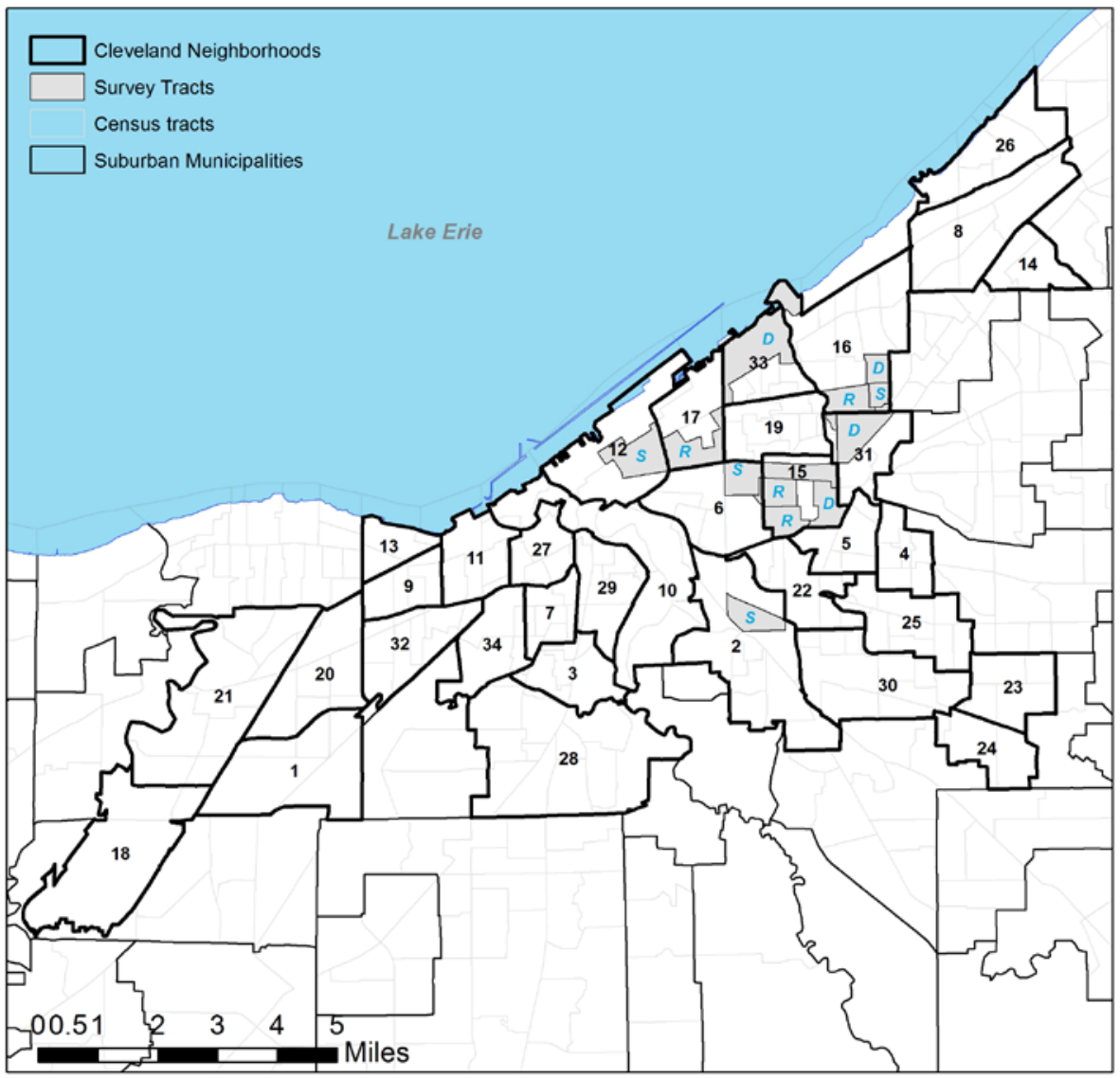

Figure 2.1: Map of Cleveland neighborhoods with surveyed tracts indicated

\subsubsection{Survey results}

\subsubsection{Households and employment}

Overall, our survey results indicate a diverse adult population living in the central neighborhoods of a shrinking city. ${ }^{5}$ They are long-time residents of their neighborhoods (an average of 12.7 years living in their current home) who present a mix of renters and owners (60\% of our respondents rent; 35\% own; the remainder live with family). Thirty-two percent have a high school education or less; $30 \%$ have a bachelor's or higher. The average age of our respondents is 53 and only half currently work outside the home.

The average housing costs in Cleveland vary considerably by neighborhood, but according to 2015 ACS five-year estimates, median owner costs (with a mortgage) were \$1,017 (\$366 for

\footnotetext{
${ }^{4}$ Percent of target population responding by tract: 1136.00 : 7\%; 1141.00: 7\%; 1965.00: 7\%; 1149.00: 5\%;

1187.00: 8\%; 1184.00: 8\%; 1185.00 8\%; 1183.01: 5\%; 1083.01: 3\%; 1112.02: 6\%; 1078.02: 3\%; 1131.01: 3\%

${ }^{5}$ Throughout this section, percentages may not add up to $100 \%$ due to question non-response.
} 
those without a mortgage) while median renter costs were $\$ 654$. Our survey respondents reported spending an average of $\$ 1,086$ on housing. While such costs may seem relatively affordable ${ }^{6}$ to those living outside of the Rust Belt, our respondents were spending an average $40 \%$ of their household income on housing, with one-third of our respondents reporting that they spend more than $50 \%$ of their income on housing.

Our respondents reported a variety of reasons for choosing to live where they do. Considering that nearly a third of our respondents earn less than $\$ 11,170$ per year (43\% of the city median household income), it is not surprising that the most common rationale (37\%) given was cost or price of the home. Another $15 \%$ indicated the quality of their home (6.2\%), schools (2.3\%) or neighborhood (6.4\%) was the most important reason for their decision. Three percent had no choice to make, as they either live with family or inherited their home. The remainder of the population (43\%) chose where to live based on location: $15 \%$ because it is convenient to work; $10 \%$ because it is convenient to friends and family; $8 \%$ because of proximity to public transportation and the remainder due to proximity to health care (1\%), schools (4\%), shopping (4\%), or recreation (1\%).

Only half of our respondents reported that they currently work for pay, although an additional $12 \%$ of respondents are looking for work. Of those who do not work, $10 \%$ were temporarily absent from their job; $12 \%$ were looking for work; $16 \%$ were homemakers; $6 \%$ were full-time students; $47 \%$ were retired; and 22\% were disabled. Of those who do work, however, onequarter work at two or more jobs, averaging 41 hours of work each week.

\subsubsection{Transportation access and costs}

For those who do work, the majority (57\%) drive alone using a primary vehicle to their job. Another $20 \%$ walk (12\%), bike (4\%), or carpool (4\%). The remaining $18 \%$ of respondents rely on public transit. Fifteen percent of working respondents had no vehicle available. The average distance to work is 7.8 miles or 21 minutes (we asked both time and distance). Among nonworkers, $45 \%$ have no vehicle available. Although they did not respond to the commuting-mode question, based on answers to other survey questions, we can comfortably assume that they are more dependent on public transit than their working counterparts.

We asked respondents to rank in importance five factors that might make public transit a better option for them: Close to work and home; Faster than driving; Reasonable in cost; Consistently on time; Fits your schedule. Amongst all respondents, being closer to home was most important, followed closely by transit being consistently on time and cheaper. Among just workers,

however, timeliness was the most important choice, followed by closer to work/home and fitting their schedule. Among non-workers, proximity to home and cost were by far the most important factors. This makes sense considering that $45 \%$ of non-workers have no access to an automobile compared to $15 \%$ of workers. As for transportation costs, the average spent on transportation (including car payments, fuel, insurance, transit fares, and parking) whether working or non-

\footnotetext{
${ }^{6}$ A household's housing expenses are deemed “affordable” if they do not exceed $30 \%$ of the monthly income of that household. The median household income in the city of Cleveland is $\$ 26,150$. Thus, median owner costs with a mortgage comprise of $47 \%$ of the city median; rental costs $30 \%$; and owners without a mortgage $18 \%$
} 
working is about $18 \%$ of monthly income ( $\$ 270$ overall; $\$ 365$ for workers; $\$ 157$ for nonworkers). Among those who do not have access to a car, costs comprised $22 \%$ of their monthly income.

Overall, our survey results indicate that low-income residents in shrinking cities have limited mobility — both in terms of housing and transportation. Survey respondents have lived in the same location an average of 12 years. In some areas, this may indicate housing stability and homeownership_-signs of neighborhood strength and household wealth building. But in a shrinking context, this may indicate households without many options. As populations decline, so do housing prices. Retired and disabled non-working populations will see their home declining in value, the market for their home shrinking, and neighborhood amenities disappearing. Since a significant percentage do not have access to a car and rely on public transportation, this compounds their lack of mobility.

\subsubsection{Analysis}

Our first research question asks how well the LAI estimates costs for households in shrinking cities. Based on earlier research (the previous chapter of this report), we expect the survey research to find that the LAI over-estimates at least housing costs, if not both housing and transportation costs. Answering the research question, however, is less than straightforward owing to the LAI's structure: it provides eight cost estimates for both housing and transportation, one for each of eight household types (Table 2.1). As shown below, the costs can vary substantially depending on the household type chosen. The LAI assumes all households in a tract identically match the prototypical household type. Therefore, determining how well the LAI predicts costs requires matching each tract to a household type. As this section argues, this requirement is not empirically reasonable, but given our best effort at matching each neighborhood with an LAI type, it appears the LAI overestimates both $\mathrm{H}$ and $\mathrm{T}$ costs. If LAI estimates are accurate, households in some tracts would spend nearly all income paying only housing and transportation costs. The second sub-section of our analysis presents data on how households cope with costs.

\subsubsection{Comparing LAI and survey-based estimates of housing and transportation costs}

We filtered the survey responses to identify households matching each of the LAI household types’ given household size and number of commuters. Our survey question for household income used the income ranges specified by LAI household types. For instance, the lowest income bracket was the national poverty line or below. The next was the national poverty line through $50 \%$ of the median regional household income; the third category captured households with incomes ranging from 50\%-80\% of the median regional household income. To identify Working Individual households, then, we selected households of size $=1$, with a single commuter, and an income reported in either the second or third income group. Thus, our identification of households matching the LAI types likely over-estimates the true number of matches, since we allow income to range above or below the target. Table 2.1 shows the results.

Table 2.1: LAI household types

Household Type Income Income HH \# Commuters \# Found in




\begin{tabular}{|c|c|c|c|c|c|}
\hline & & $\begin{array}{l}\text { Codes in } \\
\text { Survey }\end{array}$ & Size & & Sample \\
\hline $\begin{array}{l}\text { Median-income } \\
\text { family }\end{array}$ & MHHI & $4-5$ & 4 & 2 & 3 \\
\hline $\begin{array}{l}\text { Very low-income } \\
\text { individual }\end{array}$ & $\begin{array}{l}\text { National } \\
\text { poverty } \\
\text { line }\end{array}$ & 1 & 1 & 1 & 0 \\
\hline Working individual & $\begin{array}{l}50 \% \text { of } \\
\text { MHHI }\end{array}$ & $2-3$ & 1 & 1 & 5 \\
\hline Single professional & $\begin{array}{c}135 \% \text { of } \\
\text { MHHI }\end{array}$ & $5-6$ & 1 & 1 & 0 \\
\hline Retired couple & $\begin{array}{l}80 \% \text { of } \\
\text { MHHI }\end{array}$ & 3-4 & 2 & 0 & 13 \\
\hline Single-parent family & $\begin{array}{l}50 \% \text { of } \\
\text { MHHI }\end{array}$ & $2-3$ & 3 & 1 & 11 \\
\hline $\begin{array}{l}\text { Moderate-income } \\
\text { family }\end{array}$ & $\begin{array}{l}80 \% \text { of } \\
\text { MHHI }\end{array}$ & 3-4 & 3 & 1 & 8 \\
\hline Dual prof family & $\begin{array}{l}150 \% \text { of } \\
\text { MHHI }\end{array}$ & 7 & 4 & 2 & 1 \\
\hline
\end{tabular}

Only 41 (8.5\%) of our respondents fit into any of the LAI established household types. As one example of the disjuncture between the household types and our survey sample, consider that the only LAI household type that does not have any commuters is the retired couple. Our sample included many households without commuters ( $\mathrm{n}=155$, or $32 \%)$, but 94 of them $(60 \%)$ were a single-person household, not a couple. Additionally, $78 \%$ of those zero-commuter households reported an annual income using survey codes 1 or 2, but the retired couple LAI type matches income code 3-4. These findings indicate that the LAI household types fail to represent the vast majority of households found in Cleveland, suggesting the LAI estimates also might not align with lived experiences.

To compare LAI estimates to our survey results, we nevertheless had to categorize each study tract as one LAI type. Based on income levels and household sizes, most tracts best matched either the Single Parent type, or were debatably best matched to either the Moderate Income type or the Retired Couple type. Figures 2.2 and 2.3 compare our survey results for household and transportation costs to those estimated by the LAI for each household type. In Figure 2.2, seven tracts are matched to the Single Parent type and five to the Moderate Income type. In Figure 2.3, the Moderate Income tracts have been categorized instead as Retired Couple tracts. It is important to emphasize, however, that very few households in any tract actually match the defining characteristics of these household types. 


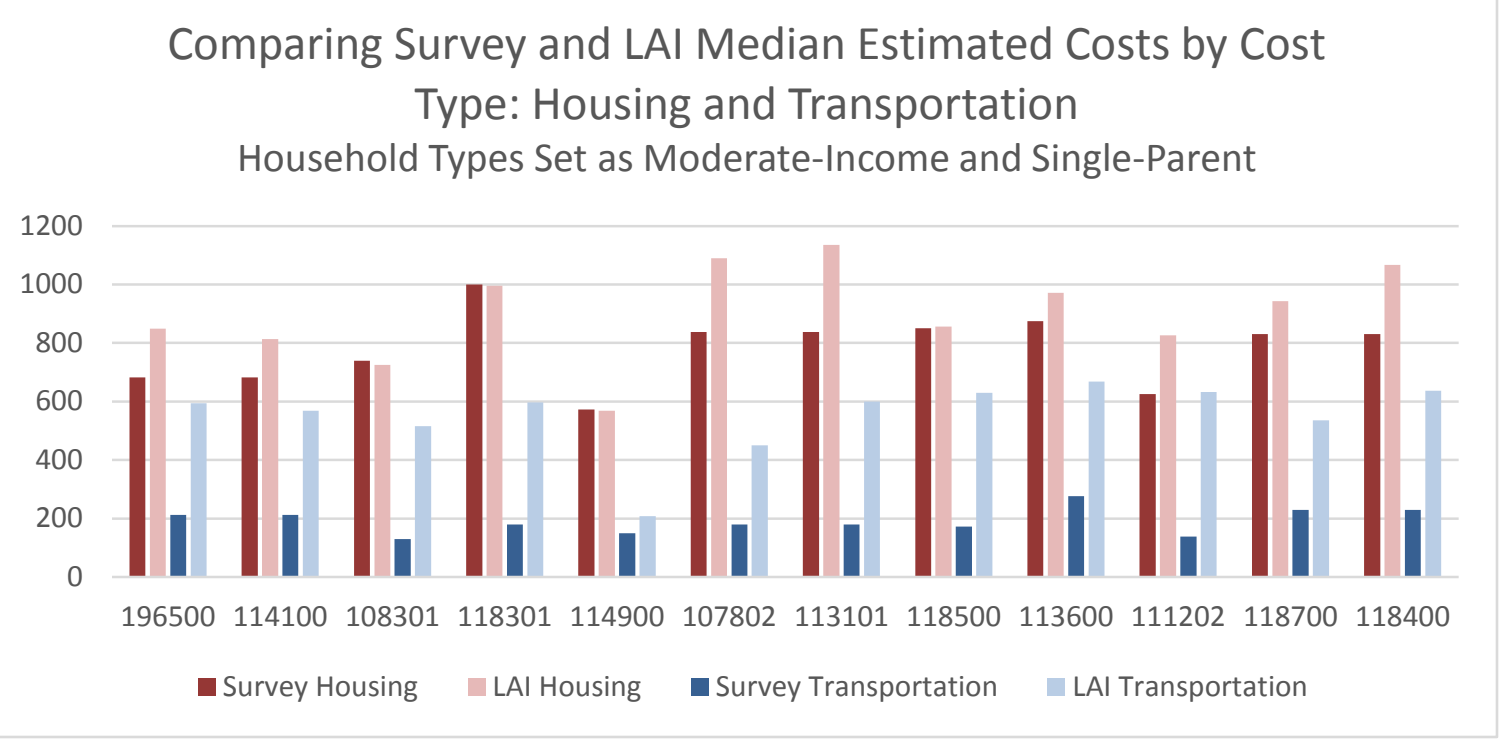

Figure 2.2: Survey results compared to LAI “moderate-income” and "single-parent" household types

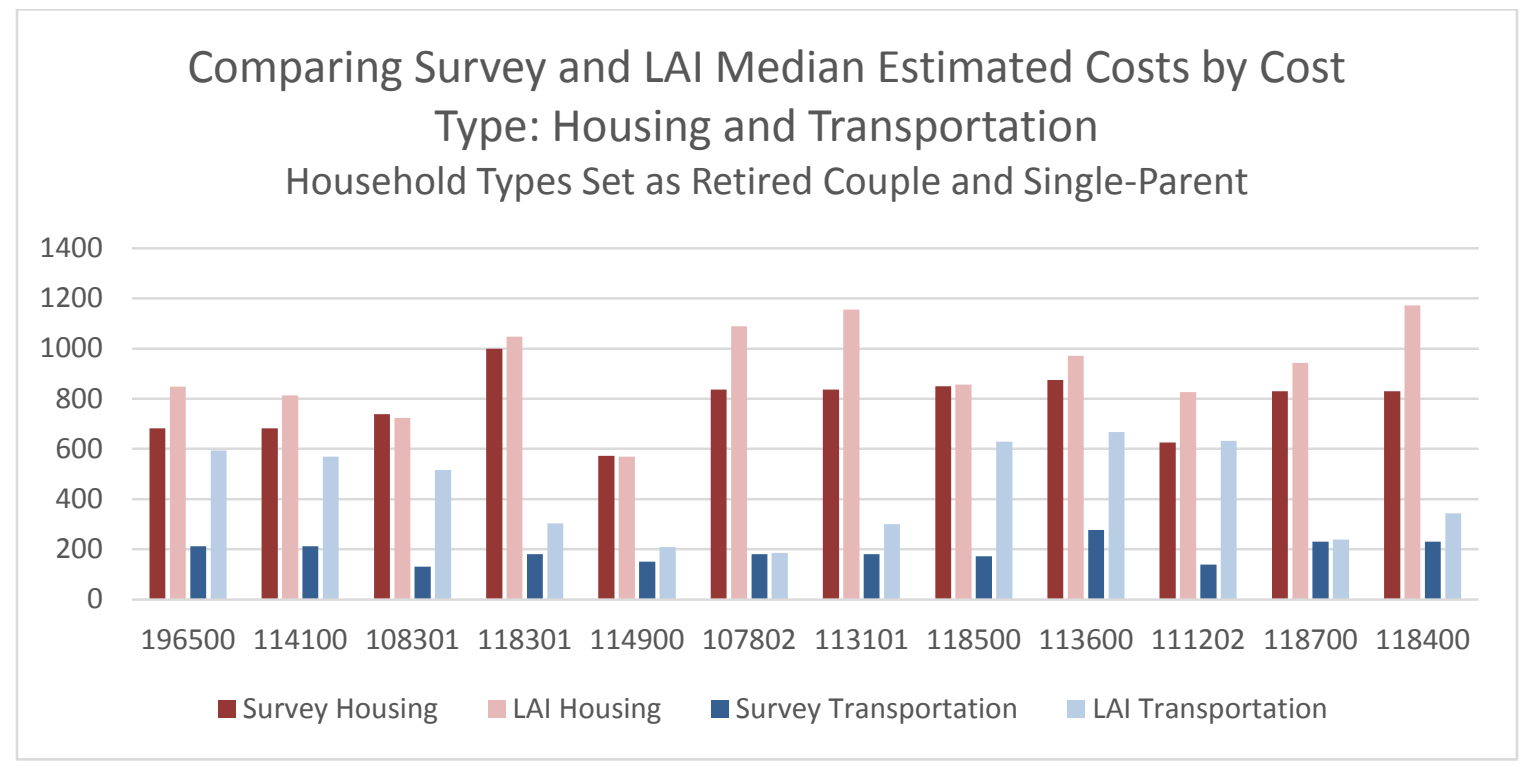

Figure 2.3: Survey results compared to LAI "retired-couple" and "single-parent" household type

As these figures show, in virtually all cases the LAI over-estimates both housing and transportation costs. The use of the retired couple type (rather than the moderate income type) reduces the difference between the survey and LAI estimates, but not enough to call them close. In this scenario (Figure 2.4), the LAI overestimates housing costs by $17.7 \%$ and transportation costs by $126.4 \%$. This outcome does not contradict expectations. Earlier research (Chapter 1 of this report) finds that the LAI likely overestimates housing by $5.6 \%$ for owners and $21 \%$ for 
renters, and that existing secondary data on transportation was too unreliable for use.

It bears mentioning that the LAI's goodness of fit relative to the survey results also depends considerably on whether the survey results are presented at their median or mean. From the perspective of the LAI, there is no distinction between an average and a median cost within a neighborhood, because all households within neighborhoods are identical; the average equals the median. Empirical data rarely if ever show this characteristic, and are typically reported at the median. Building from Figure 2.3, using Single Parent and Retired Couple household types to classify the study tracts, Table 2.2 shows the difference in cost burden based on the survey versus the LAI estimates, using the survey median versus mean.

Table 2.2: LAI estimates and comparisons to survey data

\begin{tabular}{c|cc|c|cc}
\hline Tract Number & $\begin{array}{c}\text { Median } \\
\text { Survey Result }\end{array}$ & $\begin{array}{c}\text { Survey } \\
\text { Result }\end{array}$ & $\begin{array}{c}\text { LAl } \\
\text { Estimate }\end{array}$ & $\begin{array}{c}\text { Total } \\
\text { Difference: } \\
\text { Median-LAl }\end{array}$ & $\begin{array}{c}\text { Total } \\
\text { Difference: } \\
\text { Mean-LAI }\end{array}$ \\
\hline 196500 & $\$ 895$ & $\$ 1,076$ & $\$ 1,443$ & $-\$ 549$ & $-\$ 367$ \\
114100 & $\$ 895$ & $\$ 1,076$ & $\$ 1,383$ & $-\$ 488$ & $-\$ 307$ \\
108301 & $\$ 869$ & $\$ 1,189$ & $\$ 1,240$ & $-\$ 371$ & $-\$ 51$ \\
118301 & $\$ 1,180$ & $\$ 1,385$ & $\$ 1,351$ & $-\$ 171$ & $\$ 34$ \\
114900 & $\$ 723$ & $\$ 1,127$ & $\$ 1,489$ & $-\$ 766$ & $-\$ 362$ \\
107802 & $\$ 1,018$ & $\$ 1,819$ & $\$ 1,276$ & $-\$ 259$ & $\$ 543$ \\
113101 & $\$ 1,018$ & $\$ 1,819$ & $\$ 1,456$ & $-\$ 438$ & $\$ 363$ \\
118500 & $\$ 1,023$ & $\$ 1,360$ & $\$ 1,485$ & $-\$ 463$ & $-\$ 125$ \\
113600 & $\$ 1,151$ & $\$ 1,380$ & $\$ 1,639$ & $-\$ 488$ & $-\$ 259$ \\
111202 & $\$ 763$ & $\$ 1,098$ & $\$ 1,460$ & $-\$ 697$ & $-\$ 362$ \\
118700 & $\$ 1,060$ & $\$ 1,368$ & $\$ 1,181$ & $-\$ 121$ & $\$ 187$ \\
118400 & $\$ 1,060$ & $\$ 1,368$ & $\$ 1,514$ & $-\$ 454$ & $-\$ 146$ \\
\hline \multicolumn{5}{l}{ Sum of Absolute Difference } & \multicolumn{5}{|l}{}
\end{tabular}

As Table 2.2 shows, the LAI better represents households' reported costs at the mean than at the median. However, there is a reason the U.S. Bureau of the Census, among others, reports median gross rent and median selected monthly owner costs, rather than means or averages: outliers influence averages. The use of means is not recommended for income or cost data in most empirically-based research for this reason.

\subsubsection{Assessing the trade-offs households engage in to cope with unaffordable costs}

Our second research question asked how households afford housing and transportation costs if, in fact, the LAI estimates are accurate, or if reported costs exceed the $45 \%$ considered affordable. Although our analysis indicates the LAI over-estimates both housing and transportation costs, it is nonetheless the case that only three of our 12 study tracts have a median $\mathrm{H}+\mathrm{T}$ cost burden below 45\% (Table 2.3). 
Table 2.3: $\mathrm{H}+\mathrm{T}$ affordability across neighborhoods

\begin{tabular}{l|cccccc}
\hline $\begin{array}{l}\text { Tract } \\
\text { Name }\end{array}$ & HH Income & $\begin{array}{c}\text { Housing } \\
\text { Cost }\end{array}$ & $\begin{array}{c}\text { Transportation } \\
\text { Cost }\end{array}$ & $\begin{array}{c}\text { Total } \\
\text { Cost }\end{array}$ & $\begin{array}{c}\text { Total H+T } \\
\text { Affordability }\end{array}$ \\
\hline Pink R & $\$$ & 11,663 & $\$ 682$ & $\$ 213$ & $\$ 895$ & $92.0 \%$ \\
Orange R & $\$$ & 26,924 & $\$ 739$ & $\$ 130$ & $\$ 869$ & $38.7 \%$ \\
Green R & $\$$ & 28,555 & $\$ 1,000$ & $\$ 180$ & $\$ 1,180$ & $49.6 \%$ \\
Pink S & $\$$ & 15,447 & $\$ 573$ & $\$ 150$ & $\$ 723$ & $56.1 \%$ \\
Orange S & $\$$ & 40,141 & $\$ 838$ & $\$ 180$ & $\$ 1,018$ & $30.4 \%$ \\
Green S & $\$$ & 24,475 & $\$ 850$ & $\$ 173$ & $\$ 1,023$ & $50.1 \%$ \\
Pink D & $\$$ & 26,679 & $\$ 875$ & $\$ 276$ & $\$ 1,151$ & $51.8 \%$ \\
Orange D & $\$$ & 19,486 & $\$ 625$ & $\$ 138$ & $\$ 763$ & $47.0 \%$ \\
Green D & $\$$ & 33,546 & $\$ 830$ & $\$ 230$ & $\$ 1,060$ & $37.9 \%$ \\
\hline
\end{tabular}

Building off of Agrawal's work (2011), we asked survey respondents what they would do with money saved on transportation costs. Due to the distribution of household incomes of our respondents (Figure 2.4), these tradeoffs are made not only for transportation costs, but for housing costs and other costs that are difficult to either change or forego. Nearly a third of household earn less than $\$ 11,170$ and fully one-half earn less than $\$ 24,475$ per year. Figure 2.5 shows the responses given.

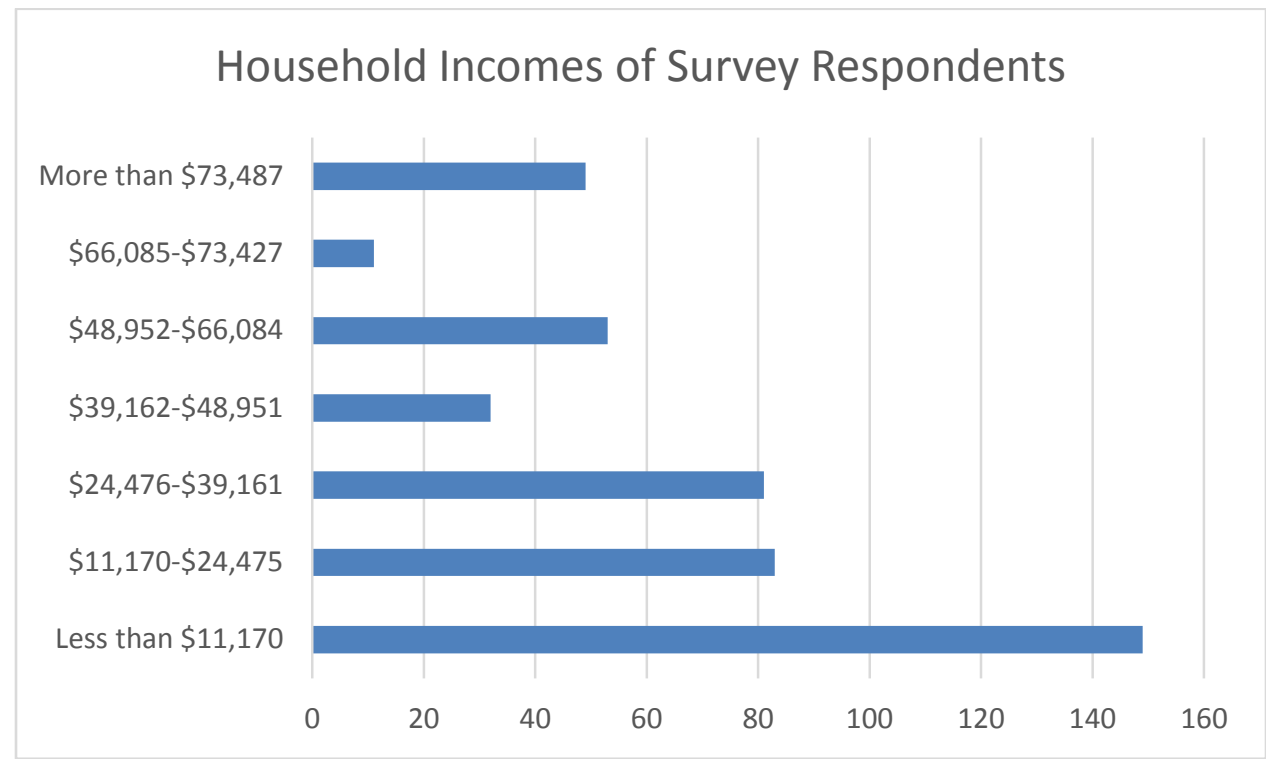

Figure 2.4: Household incomes of survey respondents 
More than $60 \%$ of respondents reported covering their costs by trading off saving or investing money, paying bills (or paying them in full), paying down debt, or purchasing household essentials. Foregoing saving or investing means foregoing future investment income or interest, household financial security in the face of unexpected expenses, or the loss to the neighborhood of the businesses residents might have invested in. Missing bill payments or paying only minimum amounts increases the cost of everyday goods and services via interest charges such as those charged by credit card companies. Another 16 respondents discussed another category of investments foregone: those in children. These respondents desired to invest in family members' educations or sometimes do simpler things to enrich children's lives, like take them on day trips. In all these cases, the long-term costs of unaffordable housing and transportation are likely significant in ways that could jeopardize households' and neighborhoods' financial security in the long run.

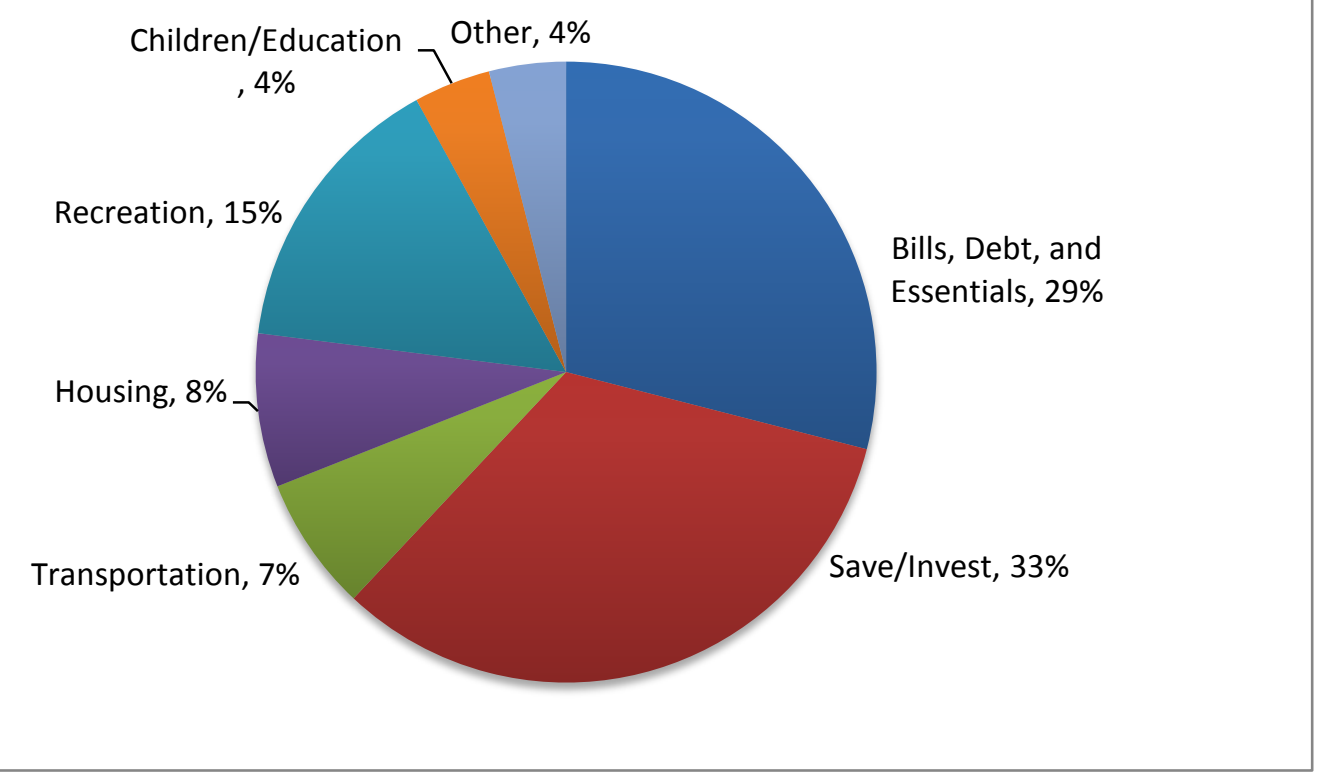

\section{Figure 2.5: Budgetary trade-offs}

Similarly, it is difficult to overstate the household-level implications of going without essentials. Thirty-four respondents said they would purchase more groceries. Others said they would pay medical co-pays, find housing (distinct from spending money to renovate or update housing, this item reflects the need to find housing), or "buy my grandson some diapers."

Among those who do not currently have a car, $10 \%$ said they would spend more on transportation, including those saying they would, "take more bus rides to different places," "ride more often” or "take [their] kids to more functions and activities.” Other respondents (8\%) said they would invest in upgrading their homes.

Relatively few responses (15\%) indicated additional funds would be used on entertainment or recreation. While the majority of responses in this category indicated a desire for vacation travel, other respondents desired simpler things such as gym memberships, sewing classes, and to purchase movies from Amazon. The rarity of intention to spend additional monies on leisure 
may correspond to the income distribution of our respondents (Figure 2.4); responses were not coded to allow us to cross-reference the incomes of respondents with their write-in answers to the question regarding tradeoffs.

\subsection{POLICY RECOMMENDATIONS}

Cleveland's Regional Transit Authority (GCRTA) faces considerable challenges exemplified by this study. Steady population decline, aging infrastructure, and shifts in job location have all presented major challenges to the GCRTA's mission of providing public transportation to the area's residents. Compounding this are ample and inexpensive parking both in downtown areas and suburban job sites as well as a lack of traffic congestion (GCRTA, 2014).

These issues face many cities in the U.S., but particularly shrinking cities such as St. Louis, Buffalo, Detroit, and Cleveland. In response, transit authorities in such cities are faced with difficult choices. Maintaining adequate service levels to all neighborhoods in the region is impossible. Some potential solutions, such as community circulators (trolley-like small busses/vans that continuously circulate through the neighborhood) have been popular in the past, but low ridership forced their cancellation outside of the downtown core in 2009 (GCRTA, 2012). In Cleveland, the GCRTA has responded by identifying core priority transit corridors, shown in Figure 2.6. While our surveyed tracts are located near a few of these corridors, many households within those areas may still face "first mile" problems of accessing the stations, posing a potential barrier to residents (Cervero, 1998; Lesh, 2013). 


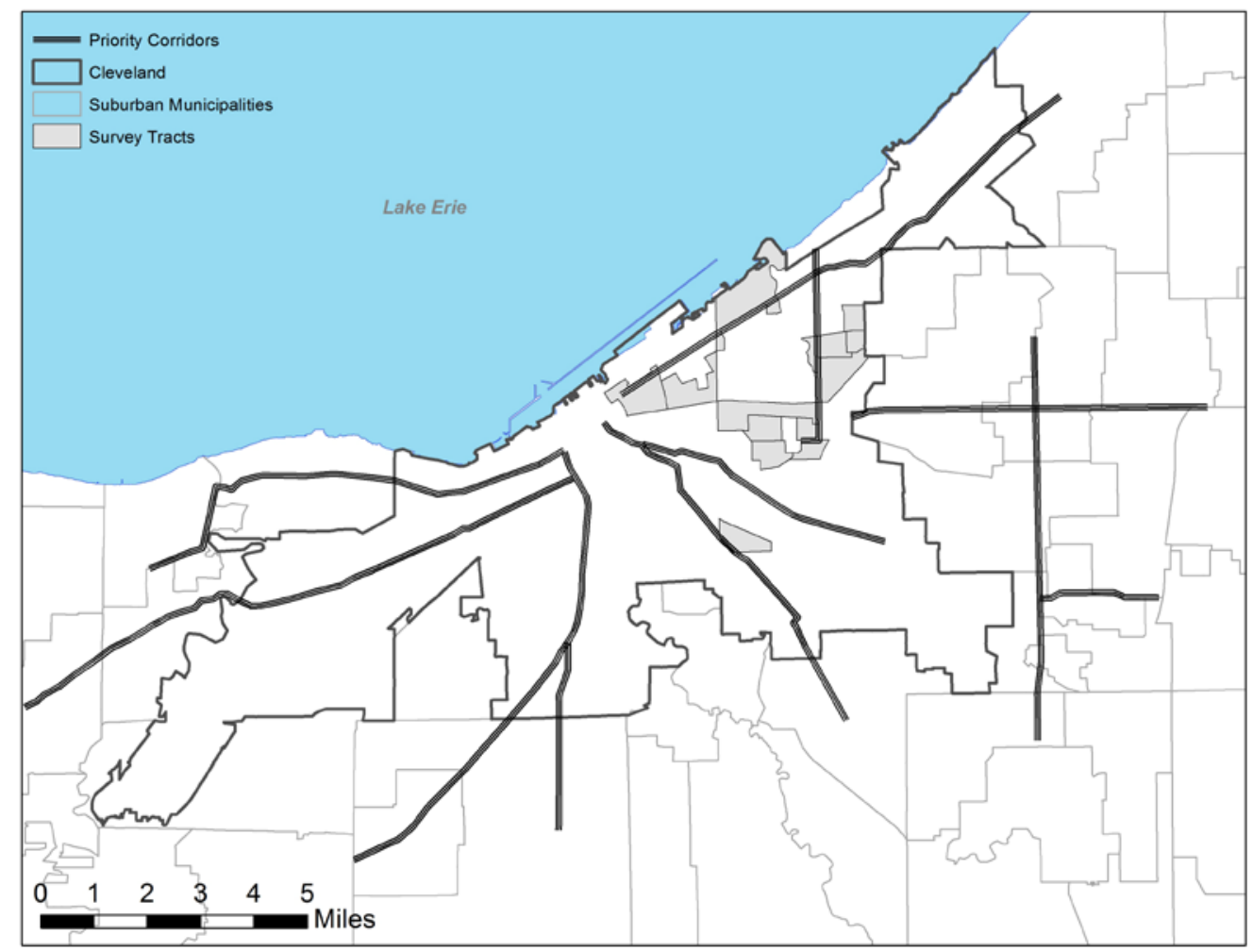

Figure 2.6: GCRTA priority corridors and survey neighborhoods

The key issue for GCRTA and similar agencies is how to provide sufficient service to those households that are not proximate to their priority corridors, particularly how to get low-income workers living in such areas to job centers. A secondary issue of particular importance to the respondents of our household survey is related to access and accessibility for retired and disabled individuals who lack access to private vehicles. The following section outlines three potential areas of interest for GCRTA, and likely also for their counterparts in other shrinking cities.

\subsubsection{Rideshare and van pools}

One of the biggest challenges for public transit service is how to overcome first/last mile issues. Distance to bus or train stops is often cited as a main reason why people do not use public transit as their primary commuting option (Canepa, 2007; Cervero, 1998; Hess, 2012; Lesh 2013). Rideshare could be effectively employed to do so, but would require explicit partnerships with public transit agencies. To date, there are few examples where private rideshare firms have partnered with public transportation agencies, but this represents a potential opportunity for future growth and partnership.

In recent years, private rideshare companies such as Lyft and Uber have become nearly ubiquitous in American cities (Henao \& Marshall, 2017; Hermawan \& Regan, 2017; Rayle et al., 2016). Such companies offer on-demand taxi-style services that can be requested via smartphone applications. Such services provide a flexible alternative to driving, but also serve workers who 
cannot rely on public transportation, such as shift workers who commute after public transit service ends. While such options provide increased choice and flexibility to those who can afford to use them, there have been few examples of their utility to low-income communities. Barriers to their application in low-income communities include not only cost, but discrimination. Unlike publicly funded transportation services, research shows that private companies like Lyft and Uber often discriminate based on a rider's race and/or the racial or class makeup of the pick-up or destination neighborhoods (Ge et al., 2016).

Vanpool or vanshare programs can be effective for getting workers to areas of concentrated employment, or to shuttle workers between existing transit lines and those job centers (Chan, 2011; Margonelli, 2011; Pointer, 2013). There are a number of different types of vanpool systems - some that rely on volunteer drivers (e.g., church vans); formal shuttle systems that can be operated either by regional transit authorities or private firms (e.g., Google Bus); and informal microbus systems (camionetas or jitneys). Each of these models could serve Cleveland neighborhoods where there are gaps in service either due to schedule or geography. According to journalist Lisa Margonelli (2011), "What's interesting about dollar vans, if they're properly licensed and insured -- and reasonably legal -- is that they could gravitate to where the riders are and where they want to go faster than public transit, which requires more infrastructure and meetings. In some cities, bus routes have histories going back decades, and they don't change to reflect how people's lives and work habits have changed."

Such models are common in immigrant communities, particularly in cities with a large Spanishspeaking population such as Los Angeles, New York, or Miami (Valenzuela, Schweitzer \& Robles, 2005). As King and Goldwyn state, “Jitney services, generally, flourish in areas or amongst groups that are excluded from planning or outright ignored by transit agencies and private operators.” (King \& Goldwyn, 2014, p. 187). These services, referred to as camionetas in Latino communities and jitneys in many other areas (King \& Goldwyn, 2014; Pointer, 2013) can be either formal and regulated or informal and unregulated. Various cities (see King \& Goldwyn, 2014) have pursued efforts at regulating or formalizing jitneys with mixed results. Regardless of whether they are formally regulated, however, they can serve as a low-cost alternative to formal transportation networks for low-income individuals (Baker et al., 2010).

\subsubsection{Bike/Ped}

Bicycling and walking are not only a growing segment of the commuter pool, but those commuters come from the same racial and income groups as transit users (Alliance, 2016). The data also suggests that immigrant households in large cities are a significant portion of pedestrian and bicycle commuters (Bhat et al., 2013). While pedestrian- and cyclist-friendly infrastructure is linked to improved health outcomes, access to those facilities is lowest in the low-income and minority communities that have morbidity rates that could be most improved (Hutch et al., 2011). Furthermore, pedestrian and cycling fatalities are highest in poor and minority neighborhoods (Cottrill \& Thakuriah, 2010). Improving cyclist safety would reduce minority communities' perceived barriers to cycling while offering potentially improved health outcomes for residents (Salis et al., 2013). 
However, planners must be sensitive to the social and political history of these communities when proposing expanded facilities, as many cities have experienced significant backlash when new routes, particularly to a central business district, are seen as a step towards gentrification (Hunter College, 2011; Zavestoski \& Agyeman, 2014). Similarly, bikeshare programs have historically ignored poor and minority neighborhoods, resulting in part in much lower usage rates (Buck, 2013; Giuliano, 2005) and fomenting distrust in the planning process (Hunter College, 2011).

Moreover, we are in an opportune time to harness the potential of improved cycling infrastructure. According to Census data, the number of bicycle commuters in Cleveland increased 314\% between 2000 and 2010. Conversely, walk commuting levels decreased by 12\% over the same period (Alliance, 2016). There are also many commuters who cycle to a transit hub (Heinen \& Bohte, 2014). However, as critics have pointed out, more could be done to encourage bicycling; in 2014 there were six bike parking rack spaces at bus stations and 52 at rail stations, versus 652 and 7,493 in Chicago (Alliance, 2016). While not every area is appropriate to designate for enhanced cycling infrastructure, low-income neighborhoods are underserved in this realm. Improving bicycling infrastructure, bicycle safety, and bicycle access through partnerships with appropriate agencies may prove to be a low-cost yet effective measure to overcome first-last mile challenges as well as improve transit access and usage in many Cleveland neighborhoods.

\subsubsection{Serving elderly and disabled populations}

One of the more surprising findings of our survey was the percentage of people living in our neighborhoods who are retired or disabled and do not have access to private vehicles. Transit agencies, including GCRTA, already provide considerable support to such populations by partnering with paratransit companies to transport individuals to work, school, medical appointments, and other necessary destinations (Cervero, 1997; Fu, 2003). However, paratransit does not cover all people in need of transportation and difficulties using regular transit services result in other public costs, suggesting that financial partnership with other federal agencies and public services might result in more efficient outcomes for all involved.

Many of the trips made by such households are for medical care. However, Medicare and Medicaid do not provide any subsidy for transit. For those who may not qualify for paratransit (such as the retired population in our study who are transit-dependent), a lack of adequate transportation results in late and missed appointments. This affects not only the individual health and well-being of the patient, but the hospital or medical provider's bottom line (Pesata et al., 1999; Wallace et al., 2015). According to one study,

“About 3.6 million Americans do not obtain medical care because of a lack of transportation in a given year. On average, they are disproportionately female, poorer, and older; have less education; and are more likely to be members of a minority group than those who obtain care. Although such adults are spread across urban and rural areas much like the general population, children lacking transportation are more concentrated in urban areas” (Wallace et al., 2015, p. 76). 
One study found that missed appointments cost roughly $\$ 200$ per patient, and nearly 20\% of all appointments are missed (Kheirkhah et al., 2016). Given that transportation issues are cited as one of the main reasons that people miss medical appointments, these cost burdens may provide some justification for establishing a transportation subsidy in conjunction with Medicare and/or Medicaid.

\subsection{ON-THE-GROUND CONCLUSIONS}

We would be remiss to conclude our paper without discussing that transit authorities such as GCRTA are in the position they currently find themselves due not only to ridership decline, but also due to sprawl and the failure of regions to take adequate action against it. The Rust Belt enactment of this scenario is perhaps best illustrated for Detroit (Galster, 2012). As he shows, ongoing land consumption at the urban fringe, without regional population growth, imposes inordinate costs on the region both economically and socially. As job centers are increasingly found in suburban locations, it becomes more of a challenge for regional transit authorities to serve the region. As such, large employment centers may need to take a greater role in providing or paying for transportation.

What seems necessary is greater connectivity among and between all modes of transportation. Currently, GCRTA is investing in servicing their priority corridors by purchasing larger buses. However, equal attention must be given to access - how to get those living in other parts of the city to those priority corridors in order to get to where they need to go. Rideshare programs can be used to shuttle residents to those priority corridors where service is more frequent and robust. Bike lanes can be planned in ways that enhance connections between neighborhoods in need and key access points on priority corridors. Bikeshare locations can be planned in ways that also connect neighborhood residents to priority bike lanes and thus to priority transit corridors. Sidewalks can also be prioritized as pedestrian corridors-linking key destinations like hospitals and job centers with existing bike and transit corridors.

However, for GCRTA to respond to the needs of the Cleveland region's diverse communities it must have accurate information. They currently rely on Census ACS data for estimates of transit ridership by Census tract, which the previous chapter of this report has shown to be unreliable. They, like researchers, continue to hope for better, more accurate data showing not only transit use by residential area, but household-level costs for transportation. Our work has shown that while the LAI itself cannot be reproduced, its estimates likely significantly overestimate transportation costs for households. Even if this were not the case, its estimates are difficult to interpret for practitioners, as they exist for household types that seldom exist in reality. We hope our survey-based data provide novel utility to the GCRTA. We also stand with them in the pursuit of better systematic estimates of location affordability. 


\subsection{REFERENCES}

Abt Associates \& Mast, B. (2015). Affirmatively Furthering Fair Housing (AFFH) data documentation. Retrieved October 7, 2016 from https://www.huduser.gov/portal/sites/default/files/docs/AFFH_Data_Documentation_12_ 31_2015.docx

Acevedo-Garcia, D., McArdle, N., Hardy, E., Dillman, K., Reece, J., Crisan, U.I., Norris, D., \& Osypuk, T.L. (2016). Neighborhood opportunity and location affordability for low -income renter families. Housing Policy Debate, 26, 607-645.

Agrawal, A.W., Blumenberg, E., Abel, S., Pierce, G., \& Darrah, C. (2011). Getting around when you're just getting by: The travel behavior and transportation expenditures of low income adults. Mineta Transportation Institute (CA-MTI-10-2806), San José State University. Retrieved March 18, 2015 from http://trid.trb.org/view/2011/M/1097942

Alliance for Biking \& Walking (2016). Bicycling and walking in the U.S. 2016 benchmarking report, January 2016. Retrieved May 21, 2017 from http://www.bikewalkalliance.org/storage/documents/reports/2016benchmarkingreport_web.p df

Baker, J., MacDonald, M., Hardwick, C. (2010). The role of taxis in improving accessibility. Association for European Transport.

Bhat, C., Paleti, R., Pendyala, R., Lorenzini, K., \& Konduri, K., (2013). Accommodating immigration status and self-selection effects in a joint model of household auto ownership and residential location choice. Transportation Research Record: Journal of the Transportation Research Board, 2382, 142-150.

Bieri, D. S., \& Dawkins, C.J. (2016). Quality of life, transportation costs, and federal housing assistance: Leveling the playing field. Housing Policy Debate, 26, 646-669.

Blumenberg, E., \& Agrawal, A. W. (2014). Getting around when you're just getting by: Transportation survival strategies of the poor. Journal of Poverty, 18(4), 355-378.

Bogdon, A. S., \& Can, A. (1997). Indicators of local housing affordability: Comparative and spatial approaches. Real Estate Economics, 25(1), 43.

Buck, D. (2013). Encouraging equitable access to public bikesharing systems. Institute of Transportation Engineers. ITE Journal, 83(3), 24.

Canepa, B. (2007). Bursting the bubble: Determining the transit-oriented development's walkable limits. Transportation Research Record: Journal of the Transportation Research Board 1992, 28-34. 
Cervero, R. (1997). Paratransit in America: Redefining mass transportation. Greenwood Publishing Group.

Cervero, R. (1998). The transit metropolis: a global inquiry. Chicago: Island Press.

Chan, N. (2011). Ridesharing in North America: Past, present, and future. Transport Reviews, 32(1), 93-112.

Cottrill, C. D., \& Thakuriah, P. V. (2010). Evaluating pedestrian crashes in areas with high lowincome or minority populations. Accident Analysis \& Prevention, 42(6), 1718-1728.

Coulton, C. J., Leete, L., \& Bania, N. (1999). Housing, transportation, and access to suburban jobs by welfare recipients in the Cleveland area. The home front: Implications of welfare reform for housing policy, 123-148.

Department of Housing and Urban Development (HUD). (n.d.-a). About the portal: Background. Retrieved November 17, 2016, from http://www.locationaffordability.info/About_Backgr ound.aspx

Department of Housing and Urban Development (HUD). (n.d.-b). About the portal: General. Retrieved July 12, 2016, from http://www.locationaffordability.info/About.aspx

Department of Housing and Urban Development (HUD). (n.d.-c). Data and methodology: Location affordability index version 2.0. Retrieved June 2, 2016, from http://www.locati onaffordability.info/LAPMethodsV2.pdf

Department of Housing and Urban Development (HUD). (n.d.-d). Location affordability index data dictionary. Retrieved June 2, 2016, from http://lai.locationaffordability.info//lai_data_dictionary.pdf

Dewar M. \& Thomas, J.M., eds. (2013). The city after abandonment. Philadelphia, PA: University of Pennsylvania Press.

ESRI (2014). The American Community Survey. Retrieved November 18, 2016 from https://ww w.esri.com/library/whitepapers/pdfs/the-american-community-survey.pdf

Fan, Y. and Huang, A. (2011). How affordable is transportation? A context-sensitive framework. Center for Transportation Studies (CTS 11-12), University of Minnesota. Retrieved March 18, 2015 from http://trid.trb.org/view/2011/M/1105078

Fu, L. (2003). Analytical model for paratransit capacity and quality-of-service analysis. Transportation Research Record: Journal of the Transportation Research Board, 1841, 81-89.

Galster, G. (2012). Driving Detroit: The quest for respect in Motown. Philadelphia, PA: University of Pennsylvania Press. 
Ganning, J. P. (2017). It's good but is it right? An under-the-hood view of the location affordability index. Housing Policy Debate, 1-18.

Ganning, J.P. \& Tighe, J.R. (forthcoming). Moving toward a shared understanding of the U.S. shrinking city” Journal of Planning Education \& Research (forthcoming).

Garson, G. D. (2015). Structural equation modeling. Asheboro, NC: Statistical Associates Publishers.

Ge, Y, Knittel, C.R., MacKenzie, D. \& Zoepf, S. (2016). Racial and gender discrimination in transportation network companies. NBER Working Paper No. 22776, Issued October 2016.

Giuliano, G. (2005). Low income, public transit, and mobility. Transportation Research Record: Journal of the Transportation Research Board, 1927, 63-70.

Greater Cleveland Regional Transit Authority (2014). Strategic Plan. Accessed May 16, 2017 from http://www.riderta.com/strategicplan

Greater Cleveland Regional Transit Authority (2012) History of public transit in Greater Cleveland. Accessed May 20, 2017 from http://www.riderta.com/history.

Greater Ohio Policy Center (2016). From Akron to Zanesville: How Are Ohio's small and midsized cities faring? Accessed April 29, 2017 from http://www.greaterohio.org/files/pdf/smlcreport-pdf.pdf.

Haas, P., Makarewicz, C., Benedict, A., \& Bernstein, S. (2008). Estimating transportation costs by characteristics of neighborhood and household. Transportation Research Record: Journal of the Transportation Research Board, 2077, 62-70.

Haas, P., Morse, S., Becker, S., Young, L., \& Esling, P. (2013). The influence of spatial and household characteristics on household transportation costs. Research in Transportation Business \& Management, 7, 14-26.

Haas, P.M., Newmark, G.L., \& Morrison, T.R. (2016). Untangling housing cost and transportion interactions: The location affordability index model-version 2 (LAIM2). Housing Policy Debate, 26, 568-582.

Hamidi, S., \& Ewing, R. (2015). Is sprawl affordable for Americans? Exploring the association between housing and transportation affordability and urban sprawl. Transportation Research Record: Journal of the Transportation Research Board, (2500), 75-79.

Heinen, E., \& Bohte, W. (2014). Multimodal commuting to work by public transport and bicycle: Attitudes toward mode choice. Transportation Research Record: Journal of the Transportation Research Board, (2468), 111-122.

Henao, A., \& Marshall, W. (2017). A Framework for Understanding the impacts of ridesourcing on transportation. In Disrupting Mobility (pp. 197-209). Springer International 
Publishing.

Hermawan, K., \& Regan, A. (2017). On-demand, app-based ride services: An emerging ground transportation mode at Los Angeles International Airport (No. 17-01061).

Hess, D. B. (2012). Walking to the bus: perceived versus actual walking distance to bus stops for older adults. Transportation, 39(2), 247-266.

Hickey, R., Lubell, J., Haas, P., \& Morse, S. (2012). Losing ground: The struggle of moderateincome households to afford the rising costs of housing and transportation. Center for Neighborhood Technology and Center for Housing Policy. Retrieved March 18, 2015 from http://trid.trb.org/view/2012/M/1218600

Hoornbeek, J. \& Schwarz, T. (2009). Sustainable infrastructure in shrinking cities: Options for the future. Center for Public Administration and Public Policy, in association with the Cleveland Urban Design Collaborative, Kent State University, Ohio.

Hunter College (2011). Beyond the backlash: Equity and participation in bicycle planning. Retrieved May 21, 2017 from http://www.hunter.cuny.edu/ccpd/repository/files/es_beyondthe-backlash-2011.pdf

Hutch, D. J., Bouye, K. E., Skillen, E., Lee, C., Whitehead, L., \& Rashid, J. R. (2011). Potential strategies to eliminate built environment disparities for disadvantaged and vulnerable communities. American journal of public health, 101(4), 587-595.

Jain, R., \& Brecher, C. (2014). Location affordability in large U.S. cities: Variability among types of households. New York, NY: Citizens Budget Commission. Retrieved from http://www.cbcny.org/sites/default/files/REPORT_LocationAffordabilitylnUS_08202014. pdf

Kaza, N., Riley, S.F., Quercia, R.G., \& Tian, C.Y. (2016). Location efficiency and mortgage risks for low-income households. Housing Policy Debate, 26, 750-765.

Kheirkhah, P., Feng, Q., Travis, L.M., Tavakoli-Tabasi, S., \& Sharafkhaneh, A. (2015). Prevalence, predictors and economic consequences of no-shows. BMC Health Services Research, 16: 13.

King, D. (2011). The (illegal) private bus system that works. Atlantic Cities. Retrieved from http://www.theatlantic.com/national/archive/2011/10/the-illegal- private-bus-system-thatworks/246166/

King, D. A., \& Goldwyn, E. (2014). Why do regulated jitney services often fail? Evidence from the New York City group ride vehicle project. Transport Policy, 35, 186-192.

Koschinsky, J., \& Talen, E. (2016). Location efficiency and affordability: A national analysis of walkable access and HUD-assisted housing. Housing Policy Debate, 26, 835- 863. 
Lens, M.C., \& Reina, V. (2016). Preserving neighborhood opportunity: Where federal housing subsidies expire. Housing Policy Debate, 26, 714-732.

Lesh, M. C. (2013). Innovative concepts in first-last mile connections to public transportation. Urban Public Transportation Systems, 2013, (pp. 63-74).

Lipman, B, 2006, A Heavy Load: The Combined Housing and Transportation Burdens of Working Families, Center for Housing Policy, Washington DC, USA.

Litman, T. (2016). Transportation affordability. Transportation, 250, 360-1560.

Mallach, A. (2010). Facing the urban challenge: Reimagining land use in America's distressed older cities - the federal policy role. Washington, DC: Brookings Institution.

Margonelli, L. (2011). Thinking outside the bus." The New York Times. November 17, 2011. http://opinionator.blogs.nytimes.com/2011/11/17/thinking- outside-the-bus/

McMillan, A., \& Chakraborty, A. (2016). Who buys foreclosed homes? How neighborhood characteristics influence real estate-owned home sales to investors and households. Housing Policy Debate, 26, 766-784.

Munger, K. (2002). Manual: Running SEM in AMOS. Retrieved November 21, 2016 from https://krmunger.files.wordpress.com/2007/09/amos_sem-manual2.pdf

National Conference of State Legislatures. (2011). Recent livability initiatives in Minnesota: An analysis. Retrieved November 17, 2016, from http://www.ncsl.org/research/transportation/recent-state-livability-initiatives-inminnesota.aspx

Nguyen, M.T., Webb, M., Rohe, W., \& Noria, E. (2016). Beyond neighborhood quality: The role of residential instability, employment access, and location affordability in shaping work outcomes for HOPE VI participants. Housing Policy Debate, 26, 733 -749 .

Pendall, R., Hayes, C., Dawkins, C., Jeon, J. S., Knaap, E., Blumenberg, E., \& Smart, M. (2015). Driving to opportunities: Voucher users, cars, and movement to sustainable neighborhoods. Cityscape, 17(2), 57.

Pesata, V., Pallija, G., \& Webb, A. A. (1999). A descriptive study of missed appointments: families' perceptions of barriers to care. Journal of Pediatric Health Care, 13(4), 178182.

Pointer, S. (2013). Reinventing the Jitney in St. Louis. Masters thesis: Ball State University. Retrieved from http://cardinalscholar.bsu.edu/bitstream/123456789/197248/1/PointerS_2013- 2_BODY.pdf.

Rayle, L., Dai, D., Chan, N., Cervero, R., \& Shaheen, S. (2016). Just a better taxi? A surveybased comparison of taxis, transit, and ridesourcing services in San Francisco. Transport 
Policy, 45, 168-178.

Renne, J.L., Tolford, T., Hamidi, S., \& Ewing, R. (2016). The cost and affordability paradox of transit-oriented development: A comparison of housing and transportation costs across transit-oriented development, hybrid and transit-adjacent development station typologies. Housing Policy Debate, 26, 819-834.

Rogoff, P. (2011). National transit summaries and trends. National Transit Database. Federal Transit Administration, U.S. Department of Transportation. Retrieved July 8, 2016, from https://www.transit.dot.gov/sites/fta.dot.gov/files/docs/NTST\%20for\%20RY\%202010.pdf

Sallis, J. F., Conway, T. L., Dillon, L. I., Frank, L. D., Adams, M. A., Cain, K. L., \& Saelens, B. E. (2013). Environmental and demographic correlates of bicycling. Preventive medicine, 57(5), 456-460.

Sanchez, T., \& Brenman, M. (2007). The right to transportation: Moving to equity. Chicago, IL: Planners Press.

Sanchez, T. W., Makarewicz, C., Hasa, P. M., \& Dawkins, C. J. (2006, August). Transportation costs, inequities, and trade-offs. In The Annual Meeting of the Transportation Research Board, Washington, DC, January.

Silverman, R., Yin, L., \& Patterson, K. L. (2013). Dawn of the dead city: An exploratory analysis of vacant addresses in Buffalo, New York 2008-2010. Journal of Urban Affairs, 35(2), 131-152.

Silverman, R. \& Patterson, K. (2016). Affordable housing in U.S. shrinking cities: From neighborhoods of despair to neighborhoods of opportunity? Policy Press.

Tighe, J.R. \& Ganning, J. (2015). The divergent city: Unequal and uneven development in shrinking cities. Urban Geography, 36(5).

Tighe, J.R., \& Ganning, J.P. (2016). Do shrinking cities allow redevelopment without displacement? An analysis of affordability based on housing and transportation costs for redeveloping, declining, and stable neighborhoods. Housing Policy Debate, 26, 785-800.

Tremoulet, A., Dann, R.J., \& Adkins, A. (2016). Moving to location affordability? Housing choice vouchers and residential relocation in the Portland, Oregon region. Housing Policy Debate, 26, 692-713.

Valenzuela, A., Schweitzer, L., \& Robles, A. (2005). Camionetas: Informal travel among immigrants. Transportation Research Part A: Policy and Practice, 39(10), 895-911.

Wachs, M. (2010). Transportation policy, poverty, and sustainability: History and future. Journal of the Transportation Research Board, 2163, 5-12.

Wallace (2005). Access to health care and nonemergency medical transportation: Two missing links. Transportation Research Record: Journal of the Transportation Research Board, 
1924, 76-84.

Walter, R.J., \& Wang, R. (2016). Searching for affordability and opportunity: A framework for the Housing Choice Voucher Program. Housing Policy Debate, 26, 670-691.

Zavestoski, S., \& Agyeman, J. (2014). Incomplete Streets: Processes, Practices, and Possibilities. Routledge. 
Transportation Research and Education Center

Portland State University

1900 S.W. Fourth Ave., Suite 175

Portland, OR 97201 